Article

\title{
Optimising Window Design on Residential Building Facades by Considering Heat Transfer and Natural Lighting in Nontropical Regions of Australia
}

\author{
Zixuan Chen ${ }^{1}$, Ahmed W. A. Hammad ${ }^{1, *}$, Imriyas Kamardeen ${ }^{2}(1)$ and Assed Haddad ${ }^{3}$ (D) \\ 1 School of Built Environment, University of New South Wales, Sydney 2052, Australia; \\ zixuan.chen@unsw.edu.au \\ 2 School of Architecture \& Built Environment, Deakin University, Geelong 3217, Australia; \\ imriyas.kamardeen@deakin.edu.au \\ 3 Departamento de Construção Civil, Escola Politécnica, Universidade Federal do Rio de Janeiro, \\ Rio de Janeiro 21941-901, Brazil; assed@poli.ufrj.br \\ * Correspondence: a.hammad@unsw.edu.au
}

Received: 4 October 2020; Accepted: 13 November 2020; Published: 17 November 2020

\begin{abstract}
Windows account for a significant proportion of the total energy lost in buildings. The interaction of window type, Window-to-Wall Ratio (WWR) scheduled and window placement height influence natural lighting and heat transfer through windows. This is a pressing issue for nontropical regions considering their high emissions and distinct climatic characteristics. A limitation exists in the adoption of common simulation-based optimisation approaches in the literature, which are hardly accessible to practitioners. This article develops a numerical-based window design optimisation model using a common Building Information Modelling (BIM) platform adopted throughout the industry, focusing on nontropical regions of Australia. Three objective functions are proposed; the first objective is to maximise the available daylight, and the other two emphasize undesirable heat transfer through windows in summer and winter. The developed model is tested on a case study located in Sydney, Australia, and a set of Pareto-optimum solutions is obtained. Through the use of the proposed model, energy savings of up to $8.57 \%$ are achieved.
\end{abstract}

Keywords: multi-objective; optimisation; Revit; dynamo; Building Information Modelling; window design; window type; window position; window-to-wall ratio

\section{Introduction}

The built environment accounts for up to 40 percent of global energy consumption. Greenhouse gas emission is anticipated to double by 2030 if no actions are taken [1]. Among all sectors in the built environment, residential buildings alone is anticipated to consume $13 \%$ of the total energy delivered in 2040 [2]. In Australia, residential buildings can be roughly categorised into any standalone single dwellings for domestic or residential purposes and multi-unit apartment buildings [3]. In the past thirty years, the average residential energy usage per person experienced a $20 \%$ increase [4]. Building performance varies notably across countries and regions. With this in mind, there needs to be alternative measures adopted to enhance the sustainability of buildings based on the local climate of the region in which they are built. Building design offers a great opportunity to address energy consumption involved. Passive design is believed to be the most effective strategy to improve building energy performance [5]. Passive design features can achieve around 30\% reduction in energy expenditure [6]. In Australia, this figure was reported to be as high as $58 \%$ for a typical residential house [7]. In particular, the glazing system, regarded as an important design consideration, is responsible for approximately $47 \%$ of total energy loss from the residential building envelope; this is 
attributed to the comparatively high thermal conductivity values of windows [8], which can lead to more extensive use of mechanical heating and cooling. An early study found that US residential windows contribute to $32 \%$ of the total building heating ventilation and air conditioning (HVAC) load [9]. By nature, windows have weak thermal effects, causing undesirable heat loss in cold climates and heat gain in warmer regions [10]. Studying the impact that windows have on energy loss requires an understanding of associated intrinsic optical properties [11], including Visual Light Transmittance (VLT), Solar Heat Gain Coefficient (SHGC) and Overall Heat Transfer Coefficient (U value). One square meter of double-glazing window can lose more than ten times as much heat as the same area of a properly insulated wall [12]. The authors of [13] investigated the impact of window sizes on building thermal load and reported that the energy load went up $45 \%$ by replacing an opaque wall with a glass façade. That said, smaller window areas could influence the amount of natural light and its distribution in the interior, thus affecting the energy requirement for artificial lighting [14].

Glazing type is reported as one of the most influential passive window design factors [15]. Arasteh [16] reviewed the advancement of glazing technology, focusing on modifications done in terms of glass properties for thermal and lighting purposes. Cheung et al. [17] studied glazing types' influence on a passive envelope design in hot and humid climates and reported a $4.6 \%$ reduction in annual cooling load by applying reflective coating on glazing. In more recent years, energy saving potentials were also identified when upgrading the single glazed window to a new reflective, solar control glass [18]. In terms of window positioning, Bokel [19] investigated impacts of window placement height on heating and cooling energy. Further, Kim et al. [13] reported a 1\% reduction on total thermal load by placing windows at a middle height.

Choosing an appropriate window design is a challenging task. On the one hand, increasing the size of windows will benefit the daylight availability [20]. At the same time, this will inevitably increase the amount of energy lost through the window [21]. As such, window properties, size and position are three highly interrelated parameters that would affect available natural daylight and heat transfer through windows [22]. The window design dilemma is extremely challenging for nontropical regions given that these areas account for more emissions and carbon footprint in comparison to tropical nations [23] and that their distinct seasonal meteorology characteristics [24] call for more diverse thermal and lighting design requirements.

To deal with window design problems, the state-of-the-art method discussed in the literature is based on a simulation-based approach [25]. However, several limitations of this approach have been identified, including the need for sophisticated training and expertise to conduct the simulations [26], the time-consuming nature of the method and its ill-adapted nature [5]. Given the time and resource constraints, along with the limited training of design and construction practitioners in these fields [27], there is a need to develop an easy-to-handle tool that caters to common building modelling software that are utilized in the field.

This paper proposes a novel approach which automatically optimizes window designs, including the window type, which extends the notion of glazing type to include the framing materials; the Window-to-Wall Ratio (WWR); and window placement height as a response to the current limitation in the literature. The aim of this research is to investigate the feasibility of conducting a numerical-based optimisation in a user-friendly modelling environment, focusing on the three design criteria mentioned above to enhance energy and daylighting aspects in nontropical regions of Australia. The objective is to deliver an optimisation tool using a common BIM platform utilized in the industry (Revit) [28] and to test the proposed approach on a case study.

This paper is structured as follows. A literature review is presented in the next section to help identify methodological limitations in the current knowledgebase and to give an overview of the thermal and lighting mechanism of windows. Following that, the research methodology and process are discussed. An optimisation framework is proposed in Revit and Dynamo [29], a Revit extension, to maximise the available daylight and to minimise undesirable heat transfer while considering the type of window, its size and its placement height. The next section presents a case study with the optimum 
design solutions visualized, and a thorough sensitivity analysis on the results is also performed. Finally, concluding remarks on passive window design strategies are offered.

\section{Literature Review}

\subsection{Optimisation Technique}

In the literature, sustainable design optimisation can be classified as either simulation-based optimisation or numerical-based optimisation [25]. Simulation-based optimisation searches for the optimum design criteria based on the outcomes of a simulation [27]. Although there is several commercial optimisation software available, it is reported that they are time-consuming and not user-friendly [26]; such approaches do not seem to fit well in real-life design procedures. To fill in this gap, modelling software such as Rhino [30] and Revit are both incorporated with optimisation packages. Popular packages include Octopus [31], Galapagos [32] and Optimo [33]. Both Octopus and Galapagos are available for Grasshopper [34], a visual programming platform exclusively designed for Rhino [35]. Optimo is a plugin for Dynamo, a visual programming tool used in Revit, and is interoperable with other BIM-based services [36,37].

These software can deliver a simulation-based optimisation workflow that updates the target model with the desirable design parameters seamlessly [38,39]. A few attempts have been made to formulate different window design problems using optimisation packages in modelling environment. Table 1 summarises some key features presented in the studies and the optimisation software employed.

Table 1. Relevant studies presented in the literature.

\begin{tabular}{|c|c|c|c|c|c|}
\hline Ref. & Factor(s) Studied & Objective(s) & Method & $\begin{array}{l}\text { Optimisation } \\
\text { Software }\end{array}$ & Simulation Tool(s) \\
\hline [40] & $\begin{array}{l}\text {-Window dimensions } \\
\text {-Glazing type }\end{array}$ & $\begin{array}{l}\text { LEED Illuminance } \\
\text { Level and Annual } \\
\text { Energy Cost }\end{array}$ & Simulation-based & $\begin{array}{l}\text { Dynamo }+ \\
\text { Optimo }\end{array}$ & $\begin{array}{l}\text { Energy and Daylight } \\
\text { Simulation Package }\end{array}$ \\
\hline [41] & -Window areas & $\begin{array}{l}\text { Useful Daylight } \\
\text { Illuminance }\end{array}$ & Simulation-based & $\begin{array}{l}\text { Grasshopper }+ \\
\text { Galapagos }\end{array}$ & Honeybee and Ladybug \\
\hline [38] & $\begin{array}{l}\text {-Wall thermal properties } \\
\text {-Glazing properties } \\
\text {-Window dimensions } \\
\text { - Façade orientation }\end{array}$ & $\begin{array}{c}\text { Daylight Factor and } \\
\text { Normalized } \\
\text { Thermal Factor }\end{array}$ & $\begin{array}{l}\text { Simulation-based } \\
\text { and } \\
\text { Numerical-based }\end{array}$ & $\begin{array}{c}\text { Dynamo }+ \\
\text { Optimo }\end{array}$ & Honeybee \\
\hline [42] & $\begin{array}{l}\text {-South and north-facing } \\
\text { window width } \\
\text {-Skylight orientation } \\
\text {-Skylight dimensions } \\
\text {-Skylight location } \\
\text {-Louvre length } \\
\text {-Building depth } \\
\text {-Roof ridge location }\end{array}$ & $\begin{array}{l}\text { Useful Daylight } \\
\text { Illuminance and } \\
\text { Energy Use Intensity }\end{array}$ & Simulation-based & $\begin{array}{l}\text { Grasshopper + } \\
\text { Octopus }\end{array}$ & Honeybee and Ladybug \\
\hline [43] & $\begin{array}{c}\text {-WWR } \\
\text {-Window height } \\
\text {-Number of windows } \\
\text {-Sill height }\end{array}$ & $\begin{array}{l}\text { Useful Daylight } \\
\text { Illuminance and } \\
\text { Energy Use Intensity }\end{array}$ & Simulation-based & $\begin{array}{l}\text { Grasshopper + } \\
\text { Octopus }\end{array}$ & Honeybee and Ladybug \\
\hline
\end{tabular}

It can be concluded that the majority of previous works was carried out in Rhino/Grasshopper environment with Honeybee and Ladybug packages as the energy simulation engines, which are powered by Radiance [44], EnergyPlus programs [45] and DOE-2 [46]. As a result, previous research studies have demonstrated the possibility of building optimisation workflows using either Rhino/Grasshopper or Revit/Dynamo. Note that the energy and daylight simulation packages in Dynamo are customized [40] and are not available to the public. The challenge is further exacerbated due to the fact that Dynamo is reported to have occasional compatibility issues with other energy simulation plugins due to the dependency of such plugins on the Dynamo build; this is inevitable given that the plugins are mostly contributed and maintained by third party developers [47]. Despite these 
limitations, if Dynamo is adopted for a numerical-based optimisation problem, there would be minimum dependencies on external packages. This can help alleviate the problem and, hence, can lead to a more efficient workflow given that Revit/Dynamo are integrated with other BIM services $[35,40]$.

\subsection{Window Lighting and Thermal Effects}

In an early work that examined the influence of glazing on building lighting requirements and energy usage, the term effective aperture was defined as the product of WWR and VLT [48]. The same study also found that there was a negative relationship between the effective aperture and lighting energy consumption. However, as effective aperture increases, the lighting energy saving starts to level off because of constraints such as latitude and solar radiation to the site [49]. In a subsequent study, the term solar aperture, obtained by multiplying the SHGC by WWR [50], was introduced to capture the effect of solar heat gain and was coupled with effective aperture to predict the cooling and lighting energy consumption in warm regions [51]. Sullivan et al. [51] found that once the "saturation level" is reached, the cooling load continues to increase due to solar heat gain and further electricity savings can only be realised via leveraging solar aperture. Although the authors acknowledged that effective aperture and solar aperture alone are not adequate to predict the energy consumption without modelling the effects of heat loss [51], the term effective aperture nowadays is often used as an indicator of daylight availability in the interior of building spaces $[52,53]$.

Heat gain through windows occurs when solar radiation enters the interior or as the result of the conduction of heat absorbed through the window [54]. However, for nontropical regions, solar radiation is the most prominent source of heat gain $[55,56]$ while conduction contributes more to heat loss in winter times [56].

As evidenced by the literature above, there is a lack of methods that are readily available and can be easily integrated into BIM procedures. The next section will present a novel framework for automatically designing the WWR, window type and window placement height and the formulation of these design criteria. As a result, minimising undesirable summer heat gain and winter heat loss while maximising effective aperture are the objectives of the window design optimisation problem examined herein. It is critical to clarify that the detailed geometry of windows on each façade is not the focus of the study. In fact, Acosta et al. [57] demonstrated that window shape has no effect on the energy consumption of a building.

\section{Methodology}

\subsection{Optimisation Framework}

Figure 1 summarises the window optimisation framework proposed in the developed approach. Optimo is a Multi-objective Optimisation (MOO) plugin that is readily downloadable as a package in Dynamo. It employs Non-Dominated Sorting Genetic Algorithm (NSGA-II) [58], which is a multi-objective evolutionary algorithm that uses nondominated sorting. NSGA-II is one of the most commonly used algorithms in dealing with multi-objective building design problems [27]. The accuracy of Optimo has been validated by Rahmani Asl et al. [40], and it was proven to be a robust NSGA-II optimisation tool. The building needs not be designed in a particular BIM software so long as it is in the Industry Foundation Classes (IFC) file format. Stage 1 of the framework involves defining three classes of optimisation input, namely (i) optimisation variables and parameters, (ii) population size and iteration number, and (iii) fitness functions. To define the optimisation variables and parameters, Visual Programming Language (VPL) was used to interact with Revit and to extract user-defined geometries from the building model. Available design options can be listed down and then retrieved from a separate Comma-Separated Values (CSV) files. Optimo requires user inputs to specify acceptable ranges for the variables optimised.

The population size, that is defined as the total number of random values, needs to be specified as it will be used as the input for the next generation in NSGA-II. The user will also specify a targeted 
iteration that would terminate the optimisation process. fitness functions in the Optimo context refer to customised functions that evaluate the design objectives [33]. In this study, three design objectives as discussed earlier are constructed, namely, maximising effective aperture, minimising summer heat gain and minimising winter heat loss; all the objectives are formulated as part of the fitness functions in a Dynamo interpretable format using VPL, DesignScript [59] and Python.

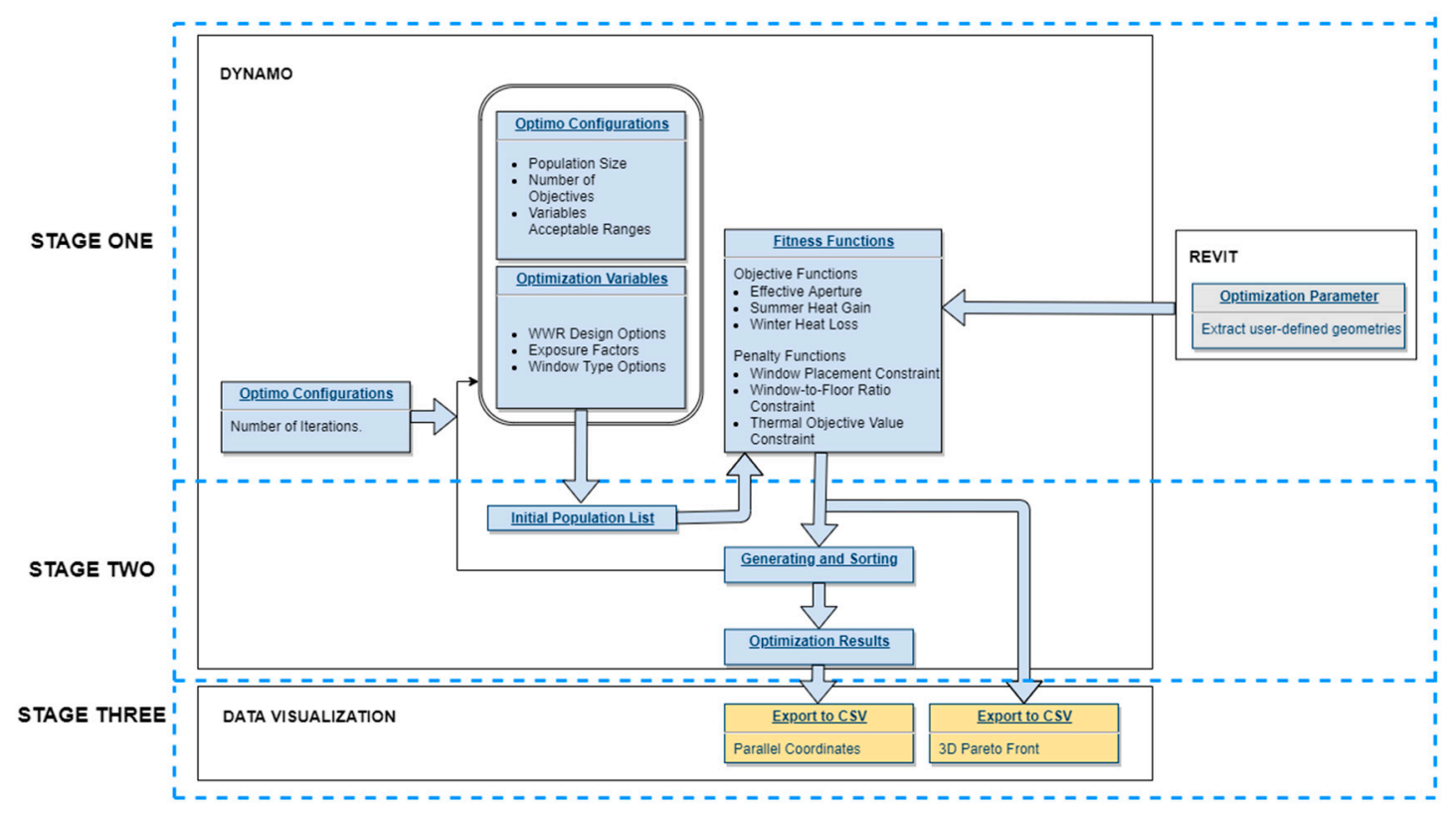

Figure 1. Proposed optimisation framework.

Penalty functions are also included in fitness functions to penalise values that do not satisfy three classes of constraints identified from the optimisation model. The first type of constraint is related to the architectural model. It defines the model boundaries for window placement. The second type specifies a Window-to-Floor Ratio (WFR) range to prevent overglazing. The third constraint draws upon the nationwide construction regulation in Australia, the National Construction Code (NCC) [56], which states the maximum value allowed for heat transfer through windows.

At stage 2 (Figure 1), a list of random values for the variables to be optimised is created as the initial generation for optimisation. This will be used as the input for the customized fitness functions, from which the results are to be evaluated using the NSGA-II algorithm. This process is iterative and only stops when it reaches the predetermined number of iterations. NSGA-II generates a spread of equally optimal solutions such that any variable cannot be further improved without compromising at least one other variable, which is commonly known as the Pareto Front. Note that, during this process, fitness function results at each generation and points on the Pareto Front are both to be exported and saved in a CSV file for further visual analysis in stage 3.

At the final stage, stage 3, the exported datapoints will be visualized for subsequent analysis. Design criteria and corresponding objective values at each generation are to be displayed in a 3-dimensional scatter plot to show improvements as the iteration proceeds. A sample of points selected from the final Pareto Front is plotted using parallel coordinates to visualize the highly interrelated design parameters.

A number of assumptions are made for the framework presented above, based on existing design practices in industry:

- On each story level, windows facing the same direction should be placed at the same height.

- The overall window system is installed with the same type of window.

- Shading devices attached on the same wall face have the same width, measured as the perpendicular distance from the edge of the shading device to the wall [56]. 
From here on, window elements discussed in this paper refer to windows located on the building envelope and their framing system.

\subsection{Computing Effective Aperture}

Effective aperture in this study is used as a measure to assess daylight availability, with a larger value indicating less reliance on artificial lights [60], contributing to potential savings in energy consumption. Since no skylights are discussed in this paper, the equation of "effective aperture for vertical fenestration" offered by Green Building Initiative (GBI) in ANSI/GBI 01-2019 [61] is adopted, where the effective aperture for windows on vertical façades is calculated as the product of the VLT value and the proportion of the window area (including framing) to the "gross wall area" [61,62], which is measured from the top of the floor to the bottom of the roof [63]. The effective aperture measured on each floor can be expressed in Equation (1):

$$
\max E A=V L T \cdot \sum_{i=1}^{n} W W R_{i}
$$

where $n$ is the total number of glazed walls on a particular level, and VLT and $W W R_{i}$ correspond to the design variables window type and the WWR scheduled for wall $i$, respectively.

\subsection{Computing Summer Heat Gain and Winter Heat Loss}

Heat gain and heat loss via solar radiation and conduction are functions of window properties and the window size, and the equations are generally calculated in Watts as given in Equation (2) [64] and Equation (3) [65], respectively:

$$
\begin{gathered}
H G^{\prime}=S H G C \cdot W A \cdot I \\
H L^{\prime}=U \cdot W A \cdot \Delta T
\end{gathered}
$$

In these two equations, $W A$ is the total window area on each story, $I$ is the solar irradiance, and $\Delta T$ is the indoor and outdoor temperature difference. Solar irradiance and temperature difference are two factors that are highly dependent on real operating conditions.

Solar irradiance can vary significantly according to the seasonal solar angle [66] and window orientations [67] and can also be manipulated by changing window positions and by adding shading devices. In other studies, this parameter relies on simulation results or direct measurement to form the basis of calculation, for example, see $[68,69]$. The value of $\Delta T$ in previous studies is often assumed as a constant based on local construction compliances [70].

In this study, in order to calculate summer heat gain and winter heat loss, a term called exposure factor introduced in NCC [56] is adopted. Exposure factors are a range of coefficients representing window exposure to the sun for different building orientations in heating and cooling seasons across all climate zones in Australia [22]. For a given climate zone and orientation, exposure factors for summer and winter design considerations are associated with a term $\frac{p}{h}$, where when the width of the shading device $p$ and the wall geometries are constants, exposure factors on each wall are only dependent on window placement height, calculated as the total wall height minus $h$, which is measured from the base of the window to the bottom of the shading device. Therefore, we can deal with discrete exposure factors instead of continuous window height variables in the optimisation. Figure 2 demonstrates how the summer exposure factor for east and southeast-facing windows can be associated with a series of $\frac{p}{h}$ coefficients. 


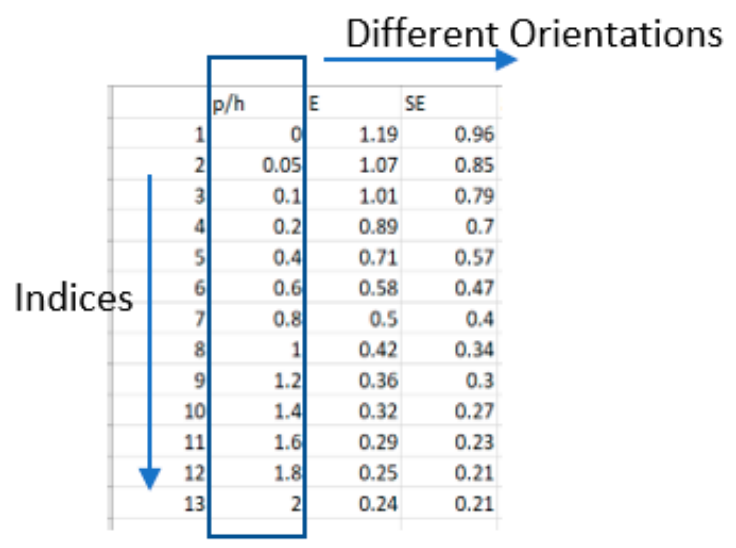

Figure 2. Example of associating exposure factors to $\frac{p}{h}$ values.

The $\frac{p}{h}$ values are also indexed in ascending order to facilitate data retrieval in the optimisation process.

Summer heat gain and winter heat loss on each level draw upon the aggregate heat gain and aggregate conductance equations given in NCC [56]. As such, objective functions shown in Equations (4) and (5) respectively are defined:

$$
\begin{gathered}
\min H G=S H G C \cdot \sum_{i=1}^{n} E S_{i} \cdot W W R_{i} \cdot A_{i} \\
\min H L=\frac{U}{S H G C} \cdot \frac{\sum_{i=1}^{n} W W R_{i} \cdot A_{i}}{\sum_{i=1}^{n} E W_{i} \cdot W W R_{i} \cdot A_{i}}
\end{gathered}
$$

where $A_{i}$ is the gross area of a glazed wall, and by multiplying it and $W W R_{i}$, the glazing area on a wall is calculated. $E S_{i}$ and $E W_{i}$ denote the summer exposure factor and winter exposure factor adopted. $E S_{i}$ and $E W_{i}$ are design variables obtained from two reference tables for summer exposure factors and winter exposure factors, respectively, which are originally obtained from the NCC and stored in CSV files following the table format shown in Figure 2. Note that, for $\frac{p}{h}$ values that are not present in the table, the next lowest $\frac{p}{h}$ value will be adopted for identifying an $E S_{i}$ while the next highest $\frac{p}{h}$ will be adopted for winter exposure factors for more stringent results [56]. This will provide us with discrete height ranges at the end of the optimisation process. In these equations, SHGC and $U$ are associated to the same window type as VLT. Equation (4) aims to minimise the heat gain in summer, while Equation (5) conveys the strategy of leveraging beneficial winter heat gain to offset heat loss.

\subsection{Model Constraints}

As discussed earlier, three classes of constraints are defined in the proposed optimisation framework. The first constraint class defines the model boundaries for window placement. The second constraint class prevents overglazing. The third constraint class imposes a maximum value allowed for summer heat gain and winter heat loss, respectively.

\subsubsection{Window Placement Constraint}

This constraint class refers to the underlying design requirement that there exists a height range on each wall that is feasible for installing a window. Considering the functionality of windows and the design feasibility, two considerations are accounted for: (i) windows should be placed above a certain working plane, and (ii) a minimum distance that is proportional to a scheduled WWR should be maintained at the top of the wall to prevent design clashes. These two constraints are defined in Equations (6) and (7), respectively:

$$
\underline{W H_{i}}=H_{i}-W P
$$




$$
\overline{W H_{i}}=H_{i}-H_{i} \cdot W W R_{i}
$$

where $\mathrm{WH}_{i}$ and $\overline{\mathrm{WH}_{i}}$ represent the lowest and highest placement points for positioning a window on a wall and $H_{i}$ is the height of the hosting wall given as a predefined parameter. The height of the working plane, WP is to be determined by the designer.

\subsubsection{Window-To-Floor Ratio (WFR) Constraint}

Equation (8) specifies a restriction on the total glazed areas on each floor by setting a lower and upper bound for the WFR to ensure feasible design. $F$ is the fully enclosed covered area of the corresponding floor, and hence, the WFR indicates the proportion of the floor to be heated via the glazing system.

$$
\underline{W F R} \leq \frac{\sum_{i=1}^{n} W W R_{i} \cdot A_{i}}{F} \leq \overline{W F R}
$$

Designers have the liberty to determine the inputs of the maximum and minimum WFR, represented by $\overline{W F R}$ and $\underline{W F R}$.

As the tolerance to WFR varies depending on the daylight factor and exterior illuminance level in the local context [71], as a general guideline, the WFR adopted can be as low as $10 \%[56,72]$ and can also go up to $50 \%[71]$ in some studies.

\subsubsection{Maximum Thermal Values Constraint}

NCC Volume Two outlines the design requirements for the maximum aggregate heat gain and aggregate conductance allowed for residential houses [56], which are the basis for the formulation of summer heat gain and winter heat loss in this study. Considering the similarities in energy use and thermal performance in all residential dwellings [73], this paper applies the same set of compliance to other residential buildings under the research scope to achieve more realistic optimisation results.

The maximum values allowed for summer heat gain and winter heat loss are given in Equations (9) and (10) below, where $C_{S H G C}$ and $C_{U}$ are deemed-to-satisfy constants offered in NCC for residential building in different climate zones [56].

$$
\begin{gathered}
\overline{H G}=F \cdot C_{S H G C} \\
\overline{C O N}=C_{U}
\end{gathered}
$$

In these equations, $F$ is the floor plate area on each floor. Equation (9) is the maximum value allowed for summer heat gain given in Equation (4), and Equation (10) nominates a constant $C_{U}$ as the upper bound on Equation (5).

\subsection{Penalty Function}

Two different approaches are adopted to handle the constraints identified above. Equations (7)-(10) are imposed using penalty functions. This can be achieved because they either restrict the objective function values or are dependent on optimisation variable selection. The lower bound of the window placement constraint as in Equation (6) is specified via design inputs.

Given that any violation on an optimisation constraint would yield an equally unfeasible design, in this study, penalties are applied without distinguishing the level of violations or the number of violations. To achieve this, a structure that is suitable to implement in Optimo is proposed to evaluate and penalize unfit results; see Figure 3. 


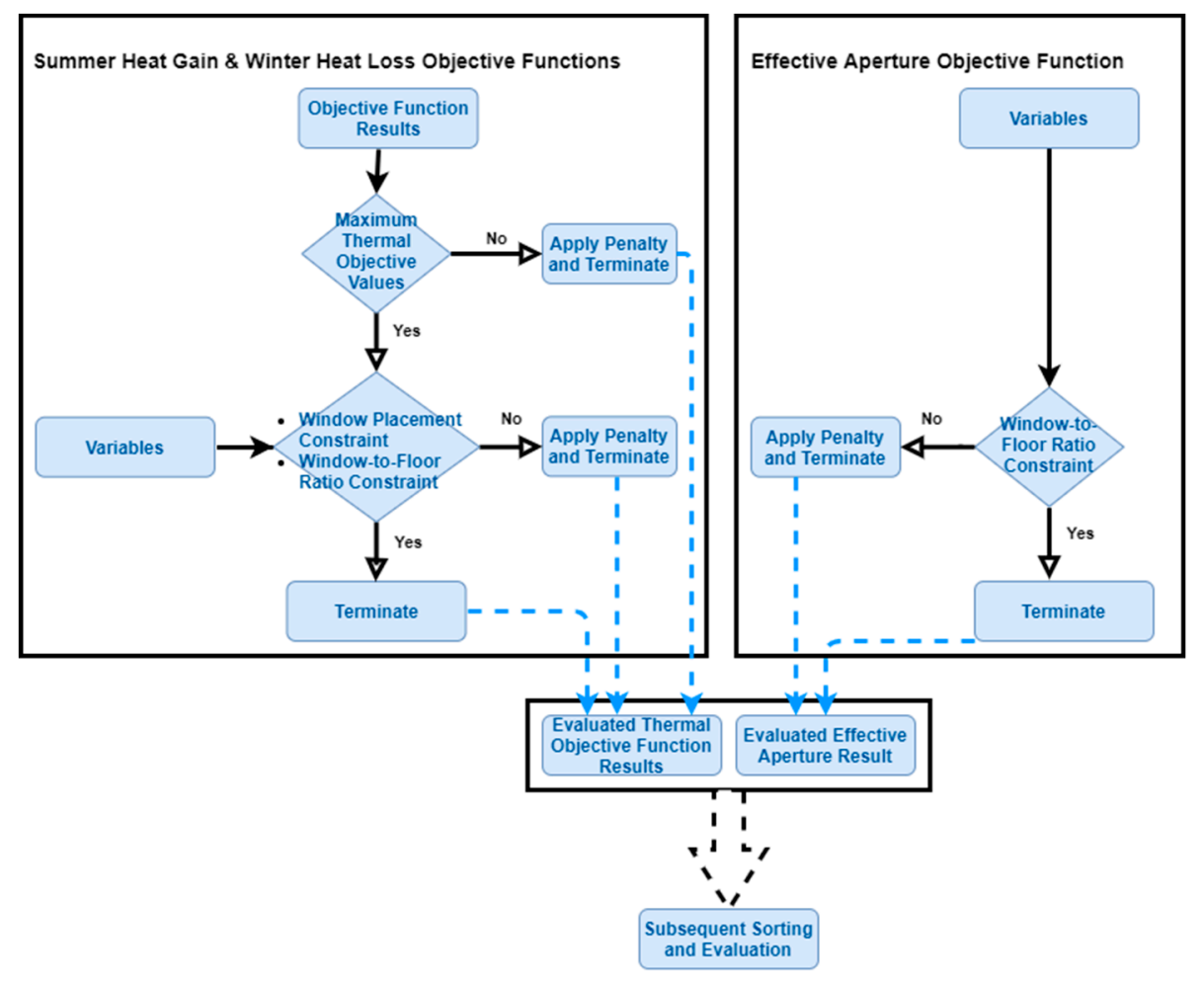

Figure 3. Penalty function structures.

Note that, although the evaluation of the summer heat gain and winter heat loss objective functions is expressed using one logical path, their evaluation process is independent.

Once the summer heat gain and winter heat loss objective function results are obtained, they are first compared with the maximum thermal objective values defined in Equations (9) and (10), respectively; if any violation occurs, a constant penalty, denoted as $P$, will be applied to the offending objective function value, leading to termination of its evaluation process at this generation. The performance of the summer heat gain and winter heat loss objective values are represented using binary variable $\delta_{g}$ and $\delta_{l}$, respectively, which will equal 1 if there is any violation. Further examination on design variables against the upper bound of the window placement constraint and WFR constraint would be executed if the preceding maximum thermal objective value is respected, meaning that the corresponding $\delta_{g}$ or $\delta_{l}$ is equal to 0 . The Boolean expressions for the window placement constraint and the WFR constraint are represented using two binary variables $\delta_{h}$ and $\delta_{f}$, respectively; for either summer heat gain or winter heat loss, any violation on these two conditions would impose the same constant penalty $P$. The effective aperture value is examined in a similar but more straightforward fashion with only the WFR constraint assessed. At each generation, only the evaluated objective function results could continue with the NSGA-II nondominated sorting and reproduction process [33]. Therefore, the proposed penalty function structure can be expressed using Equations (11)-(13):

$$
\begin{gathered}
f_{p 1}(H G)=\delta_{g} \cdot P+\left(1-\delta_{g}\right)\left(H G+P \cdot \max \left(\delta_{h}, \delta_{f}\right)\right) \\
f_{p 2}(H L)=\delta_{l} \cdot P+\left(1-\delta_{l}\right)\left(H L+P \cdot \max \left(\delta_{h}, \delta_{f}\right)\right) \\
f_{p 3}(E A)=E A+P \cdot \delta_{f}
\end{gathered}
$$

Let $f_{p 1}(\mathrm{HG})$ and $f_{p 2}(\mathrm{HL})$ be the penalty functions for summer heat gain and winter heat loss described above, and $f_{p 3}\left(\right.$ EA) aims to evaluate effective aperture. $P$ is the constant penalty $1000 . \delta_{g}, \delta_{l}, \delta_{h}$ and $\delta_{f}$ are binary variables representing four possible situations that the algorithm might encounter, i.e., 
whether $H G$ and $H L$ exceed the maximum values allowed and the violation on the window-to-floor ratio constraint and the upper bound of window placement constraint.

\subsection{Dynamo Workflow}

To execute the proposed framework, a Dynamo workflow illustrated in Figures 4-6 has been developed. The structure corresponds to the framework shown in Figure 1. The main components at each stage are grouped under their respective labels.

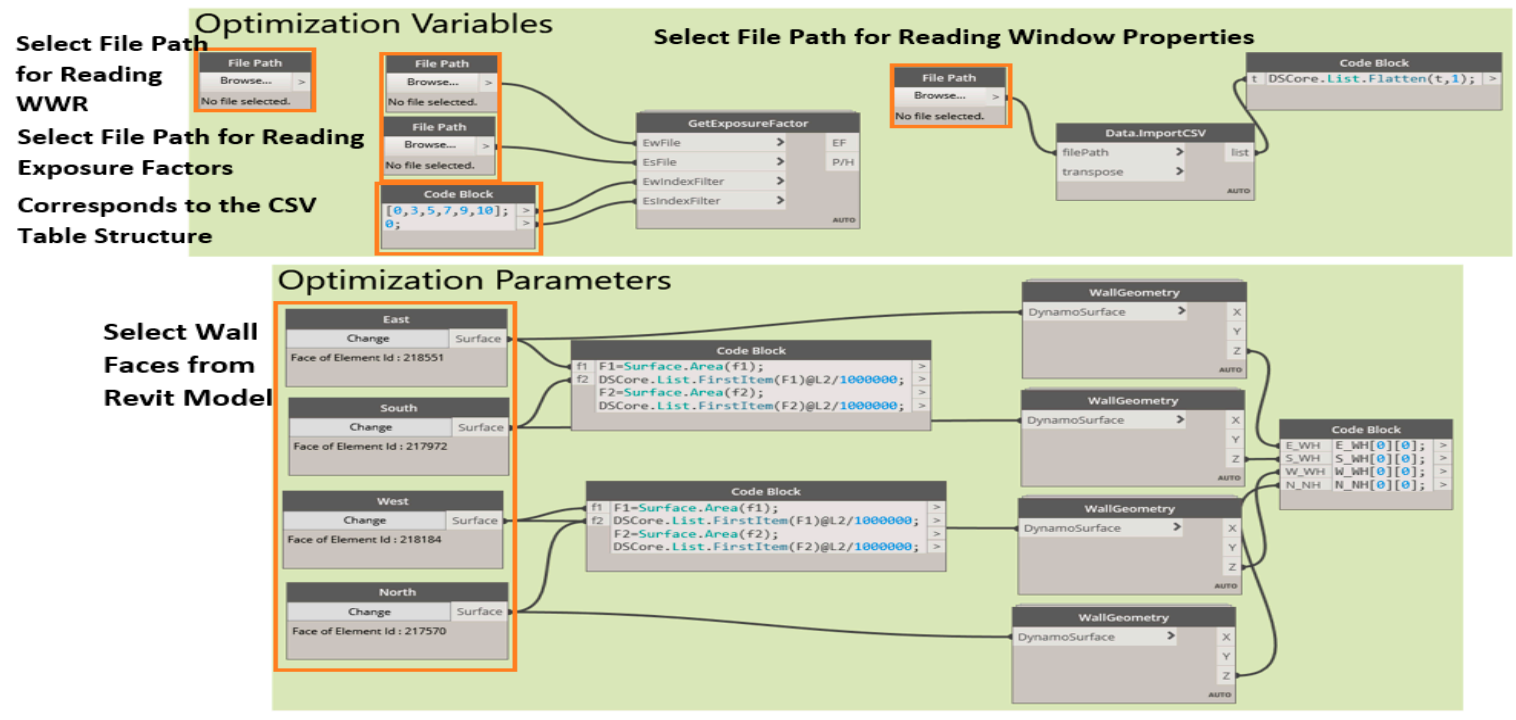

Figure 4. Dynamo workflow of obtaining optimisation inputs and parameters.

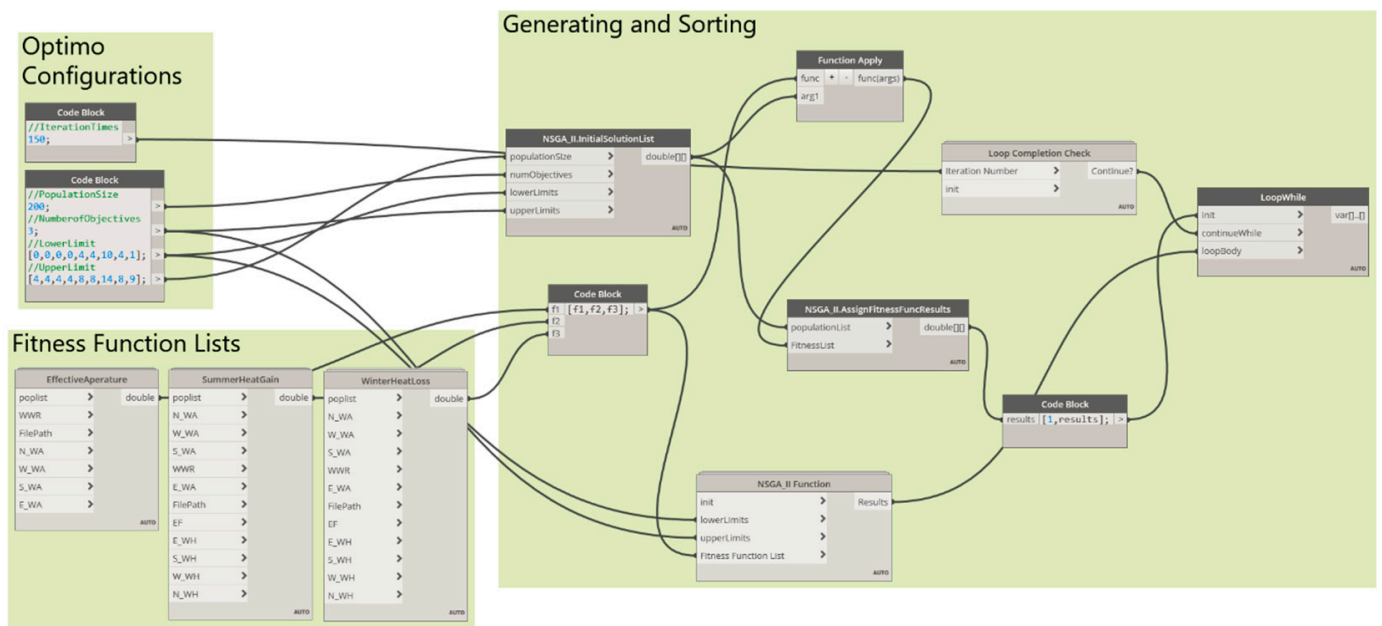

Figure 5. Dynamo workflow of optimisation setup and fitness functions. 


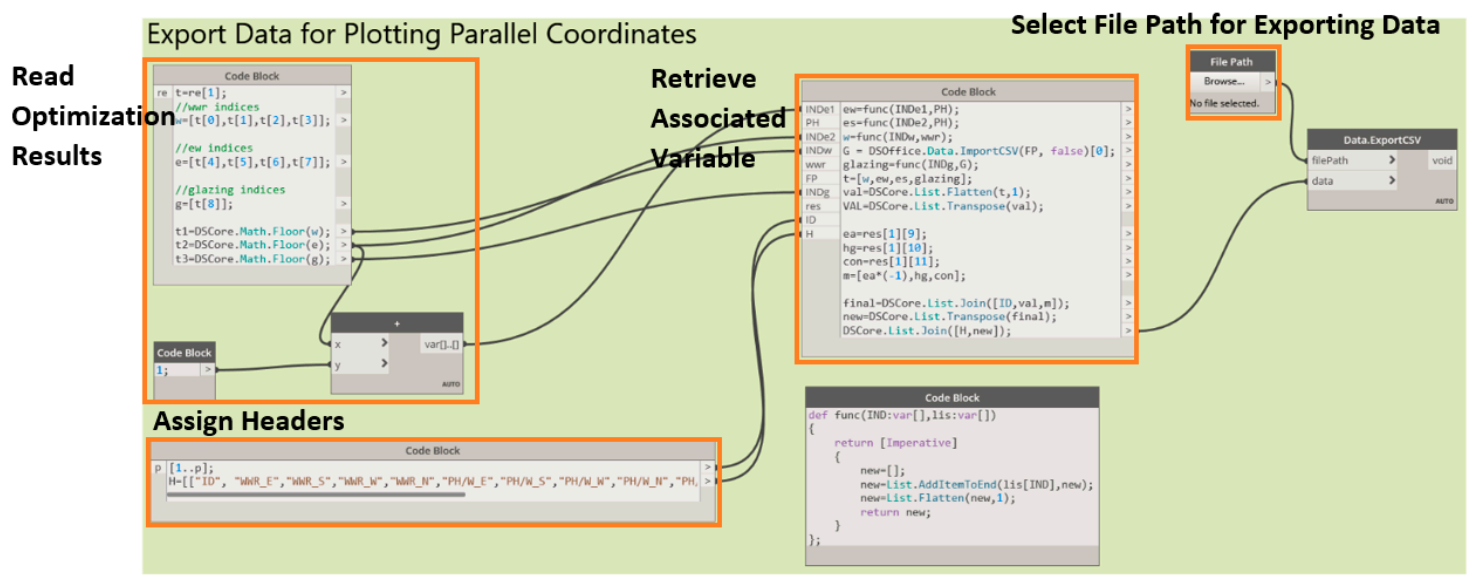

Figure 6. Dynamo workflow of exporting data for plotting parallel coordinates.

In Figure 4, under Optimisation Variables, users are asked to choose the file path where design variables are stored. It is expected that available design variables are prepared a priori and saved in CSV file format. Similarly, users are also required to select window hosting walls as highlighted in Optimisation Parameters. Figure 4 illustrates an example of selecting four glazed walls.

Data read from designated CSV files and extracted geometries in Figure 4 will be input into fitness functions; see the fitness function lists in Figure 5. Each fitness function comprises one of the design objectives discussed earlier together with penalty functions to restrict variables involved. However, fitness functions will not be able to retrieve variables without the commands labelled under generating and sorting to obtain the variable ranges specified in Optimo Configuration. In addition, generating and sorting contains the main body of the NSGA-II algorithm for sorting and evaluating fitness function results.

Figure 6 illustrates the workflow of preparing the data for plotting the parallel coordinates. This graph enables us to visualize three design objectives in a 2-dimensional space by plotting all design attributes as parallel lines [74]. As this optimisation problem involves multiple design criteria for consideration, this presentation offers a more compact way to view and compare different designs. An iterative data exportation for 3-dimensional scatter plot is achieved by including relevant codes under each fitness function. Since some design variables, such as window type and WWR, including the window height variable, could be presented as discrete values in the optimisation, each variable is handled an index by Optimo, and retrieve associated variable is where the "real" variable values are retrieved from the original CSV file.

\section{Case Study}

In order to demonstrate the applicability of the framework proposed herein, a case study of a realistic single-story house is examined in Dynamo using the proposed optimisation framework. Minor modifications were made to the BIM model for confidentiality reasons. As seen in Figure 7, the house is facing west and has a veranda and eaves for shading purposes.

The total area of the building is $59.4 \mathrm{~m}^{2}$ WWRs of $55 \%$ and $45 \%$ are scheduled for its west and north façades, respectively, and its southern- and eastern-facing walls have a WWR of $50 \%$. All windows are clear single glazing with aluminium framing and are designed with a sill height of $500 \mathrm{~mm}$. Australian regions are categorised under eight climate zones: (i) zone 1-high humidity summer, warm winter; (ii) zone 2-warm humid summer, mild winter; (iii) zone 3-hot dry summer, warm winter; (iv) zone 4-hot dry summer, cool winter; (v) zone 5-warm temperature; (vi) zone 6-mild temperature; (vii) zone 7-cool temperature; and (viii) zone 8-alpine. The project is located in a southwestern suburb of Sydney and is within climate zone 5 (warm temperate) [75]. Figure 8 indicates the plan view. 


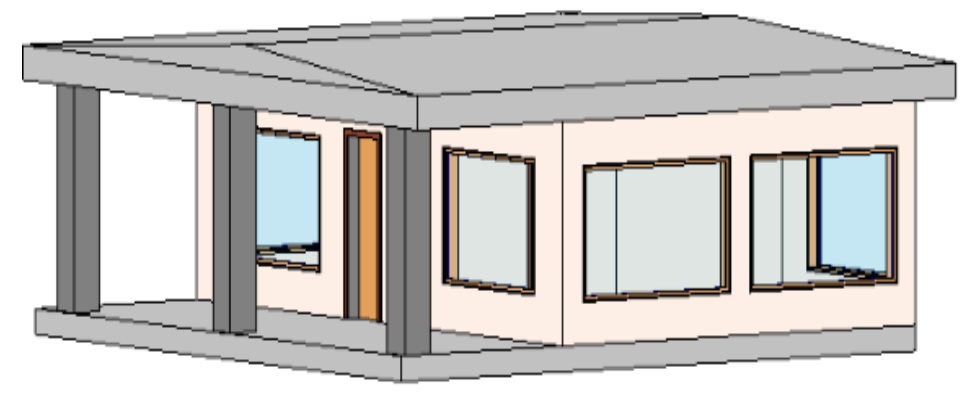

Figure 7. Visualization of the base case.

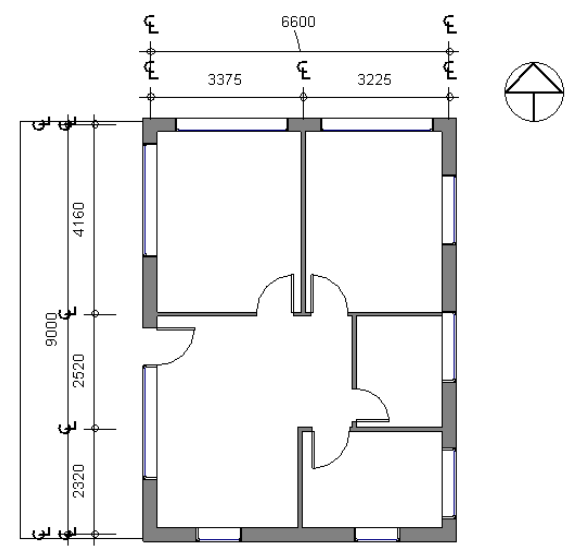

Figure 8. Floor plan.

\subsection{Variable Selection}

In many building design optimisation models, continuous variables are commonly used as they are often computationally easier to deal with compared to discrete variables [25]. However, continuous variables sometimes cannot well represent real design practices [76]. In the proposed window design problem, all design criteria were input as discrete variables to represent realistic solutions possible in industry practice. At stage 1, as shown in Figure 1, variable acceptable ranges were therefore defined according to their associated indices.

Window types used for this case study were obtained from the list of 88 default windows [77], which was developed by the Australian Fenestration Rating Council to represent performances of glazing products in the market. Four commonly used clear glass windows, namely, aluminium windows or timber/uPVC windows with either single or double glass panels [78], and their four tinted alternatives were selected, and the associated properties for the glazing and framing system are shown in Table 2. 
Table 2. Case study variables.

\begin{tabular}{|c|c|c|c|c|}
\hline \multicolumn{5}{|c|}{ Design Variables } \\
\hline \multirow{9}{*}{ WINDOW TYPE } & Type of Windows & VLT & SHGC & U-Value \\
\hline & Single Glazed Clear/Aluminium & 0.68 & 0.7 & 6.7 \\
\hline & Single Glazed Tint/Aluminium & 0.58 & 0.49 & 6.6 \\
\hline & Single Glazed Clear/Timber/uPVC/Fiberglass & 0.63 & 0.63 & 5.4 \\
\hline & Single Glazed Tint/Timber/uPVC/Fiberglass & 0.6 & 0.49 & 5.4 \\
\hline & Double Glazed Clear/Clear Air Fill/Aluminium & 0.57 & 0.59 & 4.8 \\
\hline & Double Glazed Tint/Clear Air Fill/Aluminium & 0.49 & 0.39 & 5.2 \\
\hline & $\begin{array}{c}\text { Double Glazed Clear/Clear Air Fill; } \\
\text { Timber/uPVC/Fiberglass }\end{array}$ & 0.57 & 0.56 & 3 \\
\hline & $\begin{array}{l}\text { Double Glazed Tint/Clear Air Fill; } \\
\text { Timber/uPVC/Fiberglass }\end{array}$ & 0.37 & 0.42 & 2.9 \\
\hline WWR & $20 \%$ & $30 \%$ & $40 \%$ & $50 \%$ \\
\hline \multirow{2}{*}{ HEIGHT RANGE } & $\begin{array}{c}\text { East } \\
\text { Facing }\end{array}$ & South Facing & West Facing & $\begin{array}{l}\text { North } \\
\text { Facing }\end{array}$ \\
\hline & $750 \mathrm{~mm}-2120 \mathrm{~mm}$ & $750 \mathrm{~mm}-2120 \mathrm{~mm}$ & $750 \mathrm{~mm}-2120 \mathrm{~mm}$ & $750 \mathrm{~mm}-2120 \mathrm{~mm}$ \\
\hline
\end{tabular}

As the window operating type may have an influence on the vision area, the values adopted are based on double hung, sliding, fixed and louvre windows [77]. The four WWR values tested range from $20 \%$ to $50 \%$, and this variable was incremented at a $10 \%$ interval. This was adopted with reference to a previous study that investigated the WWR of $20 \%, 30 \%, 40 \%$ and $80 \%$ on a hypothetical residential building in Sydney [79]. The study found significant influence on cooling energy consumption by increasing WWR. In this paper, considering it is recommended to reduce the WWR to a maximum of $50 \%$ for Sydney residential buildings [80], the highest input glazing ratio was set as 50\%.

An initial height range for window placement was also defined. A horizontal reference work plane, which is usually taken as $750 \mathrm{~mm}$ in Australia [81], is assumed for this case study. The maximum window placement height was determined based on the minimum possible WWR of $20 \%$ and the hosting wall height. Corresponding exposure factors for each initial height range can therefore be extracted. In addition, a WFR range of $10 \%$ to $40 \%$ is adopted to restrict glazing areas. A general design rule of thumb for WFR is $20 \%$ to $25 \%$, whereas this does not factor in the impacts of the geographical locations of different projects [82]. In this study, the lower bound $10 \%$ is a threshold for natural lighting requirements clearly stated in the NCC Volume Two [56]. Although there is no empirical data that specifies an allowance for WFR in Sydney region, a 10\% average daylight factor, which is considered the maximum allowed for the interior [83], was obtained by Ibrahim and Hayman [82] when the WFR was between $30 \%$ to $40 \%$ in Sydney. In the interest of brevity, this case study took $40 \%$ as the upper bound. However, it is acknowledged that setting $40 \%$ as the allowance is prone to yielding a larger than usual WFR. This highlights the importance for designers to determine such data as per project requirements.

Each design option shown in Table 2 has been associated with an index, and Table 3 gives the variable range input in Optimo based on the indices.

Table 3. Optimo variable inputs.

\begin{tabular}{cccc}
\hline \multirow{2}{*}{ Design Variable } & Optimo Variable Input & \multicolumn{2}{c}{ Initial Variable Input Ranges } \\
\cline { 3 - 4 } & & Lower Bound & Upper Bound \\
\hline \multirow{3}{*}{ WWR } & East Wall WWR Index & 0 & 4 \\
& South Wall WWR Index & 0 & 4 \\
& West Wall WWR Index & 0 & 4 \\
& North Wall WWR Index & 0 & 4 \\
WINDOW PLACEMENT HEIGHT & East Wall Exposure Factor Index & 4 & 8 \\
& South Wall Exposure Factor Index & 4 & 8 \\
WINDOW TYPE & West Wall Exposure Factor Index & 10 & 14 \\
& North Wall Exposure Factor Index & 4 & 8 \\
\hline
\end{tabular}


Figures 9 and 10 below provide examples of scheduling different WWRs for the western/eastern and southern/northern wall faces, where glazing systems are all placed at a minimum sill height of $75 \mathrm{~cm}$.
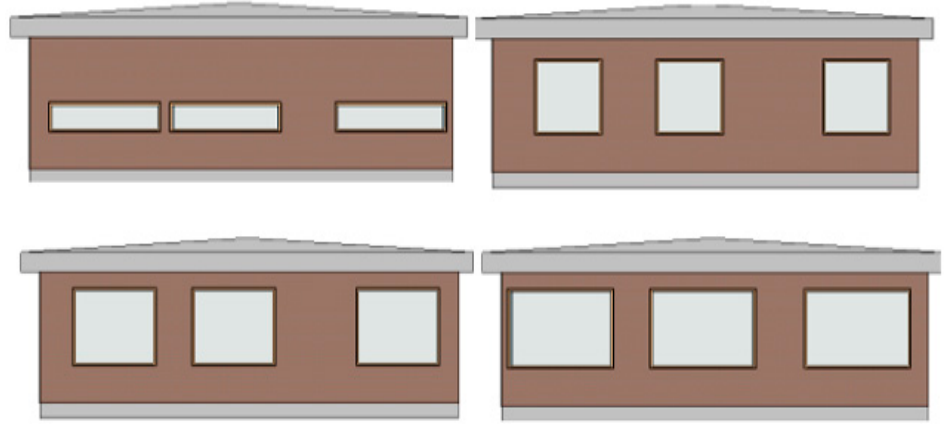

Figure 9. Illustrative example for windows placed at $750 \mathrm{~mm}$ above the floor on north/south-facing walls: elevations from top left to bottom right indicate a WWR of $20 \%, 30 \%, 40 \%$ and $50 \%$.
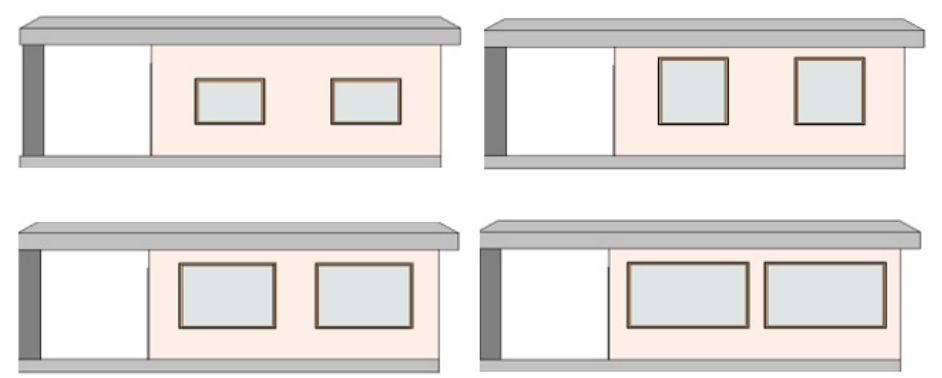

Figure 10. Illustrative example for windows placed at $750 \mathrm{~mm}$ above the floor on west/east-facing wall: elevations from top left to bottom right indicate a window-to-wall ratio (WWR) of $20 \%, 30 \%, 40 \%$ and $50 \%$.

\subsection{Results and Discussion}

The calculation process was conducted on a personal computer with a $2.5 \mathrm{GHz}$ processor and 8 GB of RAM in Windows 10 environment. The mutation and crossover probability were set as 0.01 and 0.9 , respectively. The distribution indices for crossover and mutation are 20 [40]. In this study, the Pareto Front was obtained after 150 iterations with a population size of 200. The whole process, including exporting approximately 100,000 data points, was completed within $30 \mathrm{~min}$. Figure 11 indicates the evolution of objective function values through generations.

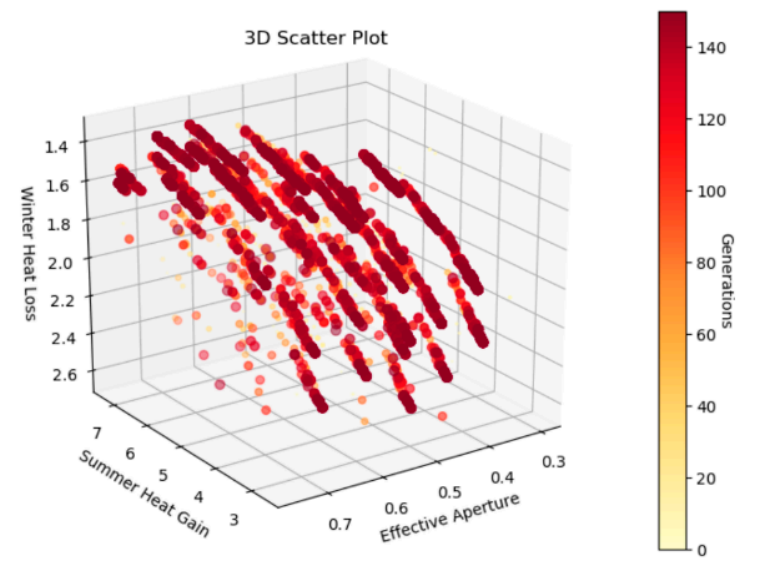

Figure 11. Improvements of the design solutions through evolution. 
In this graph, the summer heat gain, effective aperture and winter heat loss correspond to the $\mathrm{X}, \mathrm{Y}$ and $\mathrm{Z}$ axes, respectively. Generally, as the process approaches the end of optimisation, the colour of the points displayed exhibits a dark red colour scheme.

Figure 12a-c are projections of the Pareto Front onto two design objectives.

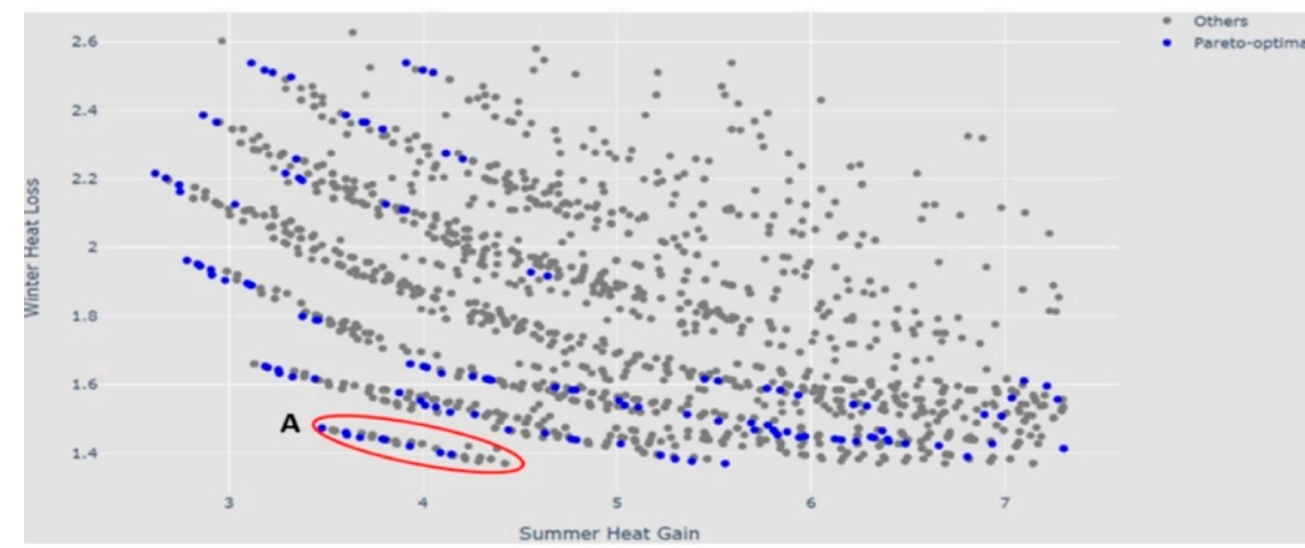

(a)

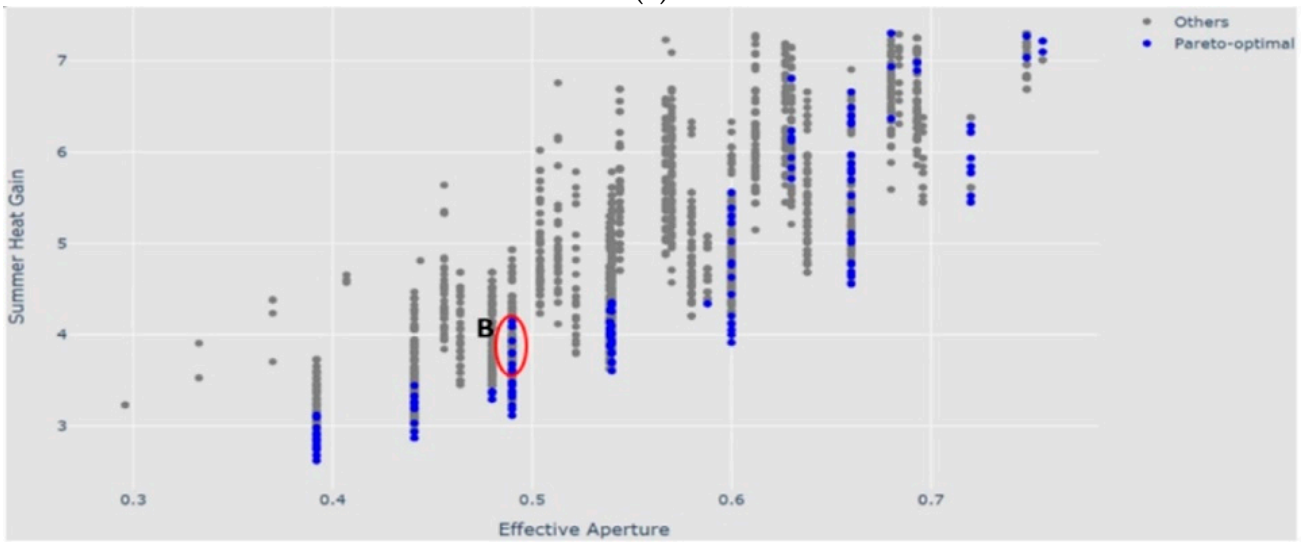

(b)

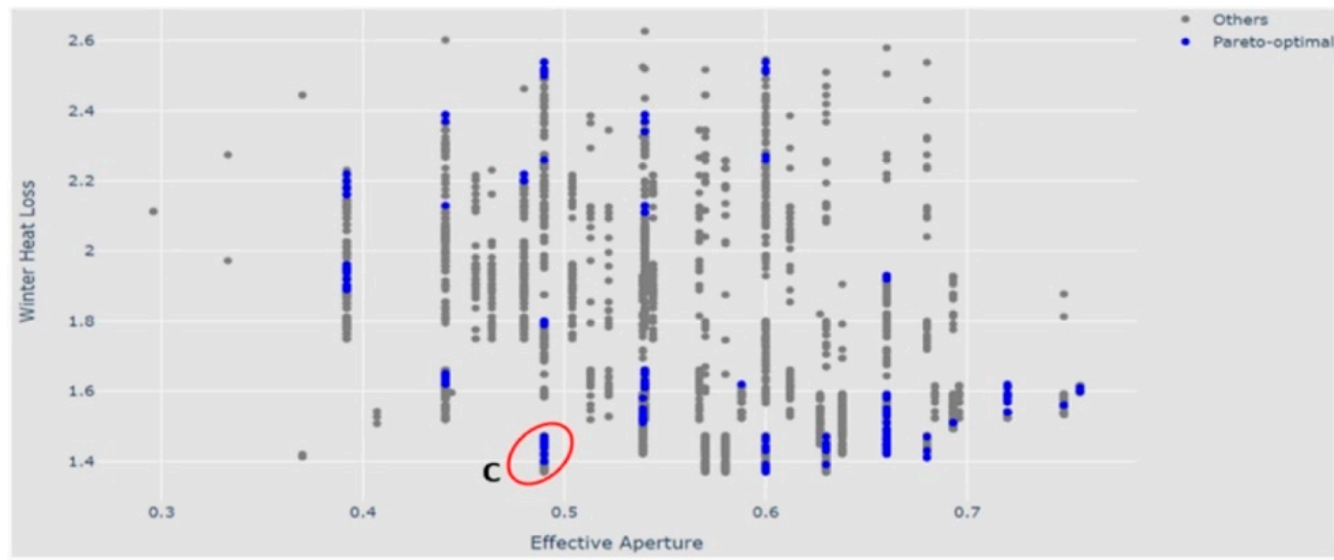

(c)

Figure 12. (a) Summer heat gain and winter heat loss, (b) Effective aperture and summer heat gain, (c) Effective aperture and winter heat loss.

Figure 12a indicates the efficacy of using winter heat gain to compensate heat loss in a warm temperate climate. Figure $12 b, c$ depicts the relationship between effective aperture and window thermal performance in summer and winter, respectively. It is observed in Figure $12 \mathrm{~b}$ that a positive relationship exists between the effective aperture and summer heat gain, which is in line with previous findings 
on effective aperture's effect on increasing cooling load [48,51]. Figure $12 \mathrm{c}$ shows a more dynamic relationship between the effective aperture and winter heat loss, where the effect of solar gain illustrated in Figure 12a also comes into play. Further, when controlling effective aperture, Figure 12b,c showed that solar gain and heat loss can be modified by changing the window height. One way to understand Figure $12 \mathrm{~b}, \mathrm{c}$ is by investigating some sample datapoints labelled as group A in Figure 12a. It can be deduced that group A represents the optimal designs when only considering the objective of minimizing summer heat gain and winter heat loss as no smaller value of either of these two objectives can be found while maintaining the performance of the other objective. Seventeen datapoints are captured in group A. The same series of data have also been highlighted in Figure $12 b, c$ as groups B and $C$, respectively. Among the 17 designs, it is found that they are all scheduled with tinted double glazing with aluminium framing and adopt the same WWR strategies, namely, 20\% to the eastern, southern and western façades and a $40 \%$ to the northern wall. Review Equation (1) for calculating the effective aperture, and it can be concluded that different values on the $\mathrm{Y}$-axis shown in groups $\mathrm{B}$ and $\mathrm{C}$ are only attributed to different window placement heights. The remaining points that have the same effective aperture values might be a result of the interaction of these three variables.

After removing six penalised values, there were 194 individuals that remained in the final generation. Figures 13 and 14 take a closer look at the optimal height range and WWR for different wall faces.

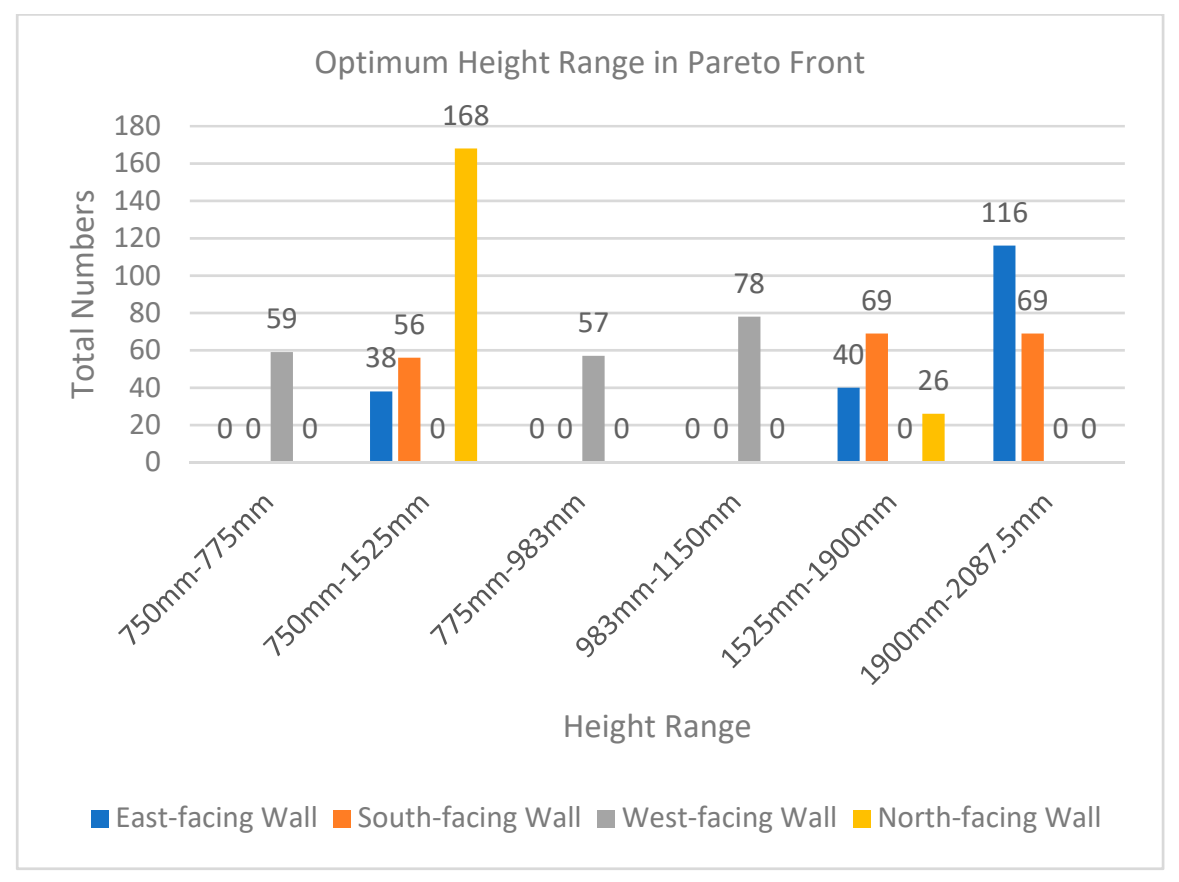

Figure 13. Optimal window height range on different walls.

It is noted that two different strategies to optimize window thermal performance can be observed from the Pareto Front. One is the common approach of minimising glazed areas on the northern façade in the southern hemisphere and placing windows at the top part of the wall to avoid heat gain. Another strategy, which has been proven to be effective according to Figure 12a is to encourage sufficient solar penetration from north-facing windows to reduce winter heat loss. Installing windows at lower heights would exaggerate this effect. As such, the intense solar radiation from the north is fully used as an alternative to mechanical heating in winter, savings from which in theory may potentially offset the additional summer cooling expenditure induced. Among all 194 solutions, around $87 \%$ of the total favour this strategy by positioning northern windows at a lower height $(750 \mathrm{~mm}-1525 \mathrm{~mm})$, and more than half of the designs also offer generous glazing areas to the north. In addition, noting that optimal design solutions tend to allocate relatively small windows $(<30 \%)$ to east-, south- and west-facing 
walls, this is reported in all cases for the eastern façade and around $90 \%$ for southern and western façades. This is in line with the strategy of taking advantage of sunlight from the north while designing small windows to these three orientations only for cross-ventilation purpose [84]. It is also observed that no WWR of $50 \%$ was recorded in the Pareto Front. One possible explanation is that WFR, shown in Equation (8), plays a prominent role in restricting the total window area.

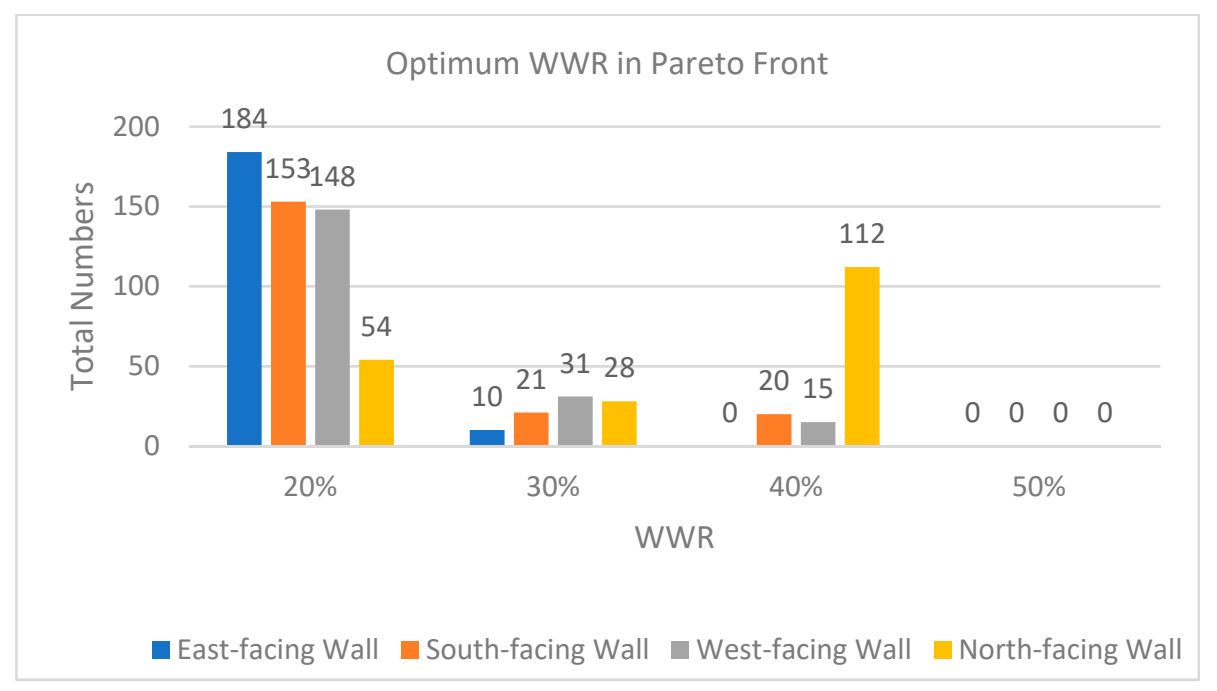

Figure 14. Optimal WWR on different walls.

\subsection{Sensitivity Analysis}

The above observations are further investigated using a sensitivity analysis. Regression is the most used sensitivity analysis technique in building energy analysis [85]. Effective aperture, summer heat gain and winter heat loss are regressed on relevant variables, and their $R^{2}$ are reported to be $0.99,0.97$ and 0.99 respectively, indicating a strong linearity in all three models. With this in mind, Standardised Regression Coefficient (SRC) is used to evaluate variable importance [25]. The positive sign of a SRC only represents a positive relationship between the design variable and the dependent design objective [86]. The importance of each variable is ranked according to the absolute value of its associated SRC. In general, larger absolute values of SRCs indicate a higher level of impact on the design criteria [42]. The results have been presented in Table 4.

Table 4. Standardised regression coefficients and importance ranking of design variables.

\begin{tabular}{cccc}
\hline \multirow{2}{*}{ Variables } & Effective Aperture & Summer Heat Gain & Winter Heat Loss \\
\cline { 2 - 4 } & & SRC (Rank) \\
\hline Wall_E & $0.076(1)$ & $0.981(1)$ & $0.060(5)$ \\
Wall_S & $0.065(2)$ & $0.423(3)$ & $0.087(4)$ \\
Wall_W & $0.057(3)$ & $0.207(7)$ & $0.145(3)$ \\
Wall_N & $0.051(4)$ & $0.419(4)$ & $-0.239(2)$ \\
Height_E & & $-0.291(5)$ & $0.031(6)$ \\
Height_S & & $-0.089(9)$ & $0.004(8)$ \\
Height_W & & $-0.099(8)$ & $0.011(7)$ \\
Height_N & & $-0.234(6)$ & $0.284(1)$ \\
Type & $-0.044(5)$ & $-0.606(2)$ & $-0.001(9)$ \\
\hline
\end{tabular}

Note that "Wall_E" and "Height_E" annotate the variables "East-facing Wall WWR" and "East-facing Window Height", respectively. In addition, as shown in Equation (1), the window height variables do not participate in the formulation of the function effective aperture; therefore, they were not computed in the effective aperture regression model. 
The results first suggest that the daylight availability is highly sensitive to the eastern and southern window sizes. In the meantime, heat gain in summer is largely determined by the size of the eastern opening and window type adopted. The high importance of eastern and southern window sizes in maximising natural daylight seems to contradict the previous finding that these two façades tend to have small windows. This is due to the thermal constraint for summer heat gain restricting such design options.

As for heating seasons, larger openings generally lead to more heat lost. However, one exception is the northern window. Further observation on the results also indicate that its height is found to have the greatest impact on winter thermal performance; hence, the plausible explanation for this is that the winter sunlight can offset heat lost. Another finding is that the design of windows on western facades make minor contribution to the heat gain as this side has extensive shading.

Four solutions were identified as a sample of the Pareto Front. The detailed window design options offered by these four designs are presented in Table 5.

Optimal window design attributes have been plotted using parallel coordinates to display a clear design trade-off, see Figure 15, where solution A, B, C and D are represented using different colours.

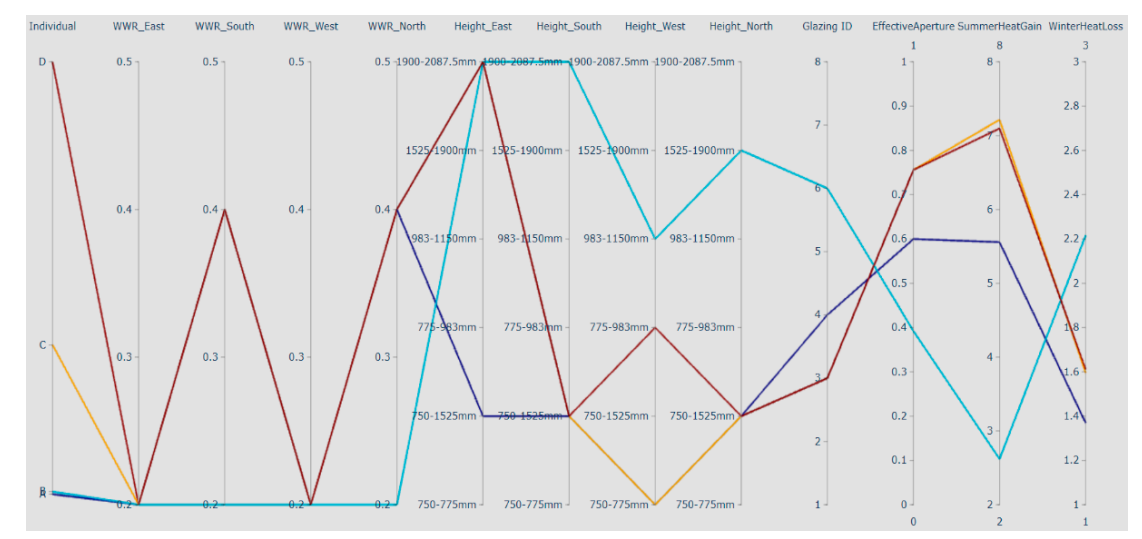

Figure 15. Parallel coordinates.

An illustrative design of each optimal solution was reinstated in the case study model, and Revit Insight [87] was used to run an energy simulation to validate each scenario. The energy simulation results have been displayed in Figure 16.

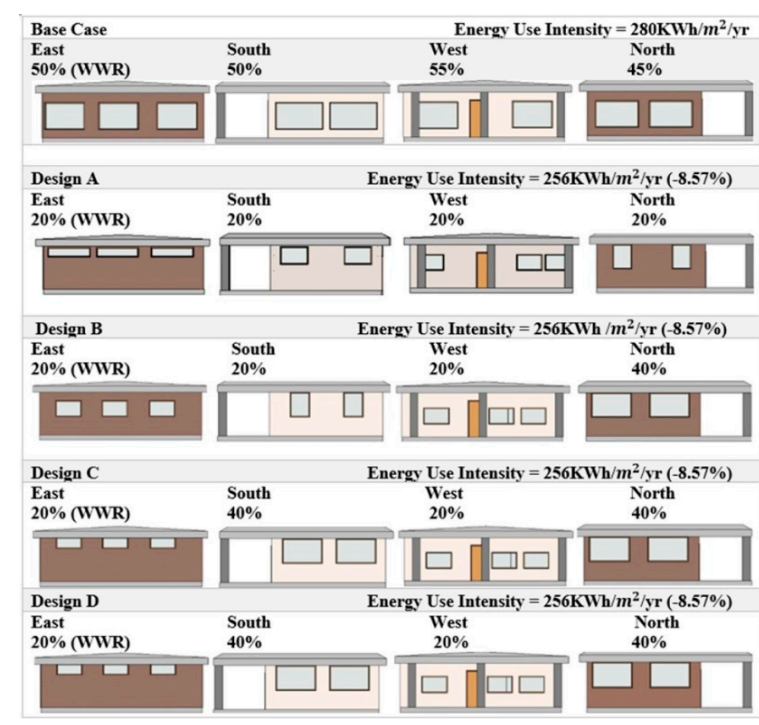

Figure 16. Illustrative example of sample designs A to D. 
Table 5. Window design solutions chosen from points on Pareto Front.

\begin{tabular}{|c|c|c|c|c|c|c|c|c|c|}
\hline & \multicolumn{2}{|c|}{ East-Facing Wall } & \multicolumn{2}{|c|}{ South-Facing Wall } & \multicolumn{2}{|c|}{ West-Facing Wall } & \multicolumn{2}{|c|}{ North-Facing Wall } & \multirow{2}{*}{ Glazing Type } \\
\hline & WWR & Height Range & WWR & Height Range & WWR & Height Range & WWR & Height Range & \\
\hline A & 0.2 & 1900-2087.5 mm & 0.2 & $1525-1900 \mathrm{~mm}$ & 0.2 & $983-1150 \mathrm{~mm}$ & 0.2 & $750-1525 \mathrm{~mm}$ & $\begin{array}{c}\text { Double Glazed Tint/Clear Air } \\
\text { Fill/Aluminium }\end{array}$ \\
\hline B & 0.2 & $750-1525 \mathrm{~mm}$ & 0.2 & $750-1525 \mathrm{~mm}$ & 0.2 & $750-775 \mathrm{~mm}$ & 0.4 & $750-1525 \mathrm{~mm}$ & Single Glazed Tint/Timber/uPVC/Fiberglass \\
\hline $\mathrm{C}$ & 0.2 & 1900-2087.5 mm & 0.4 & $750-1525 \mathrm{~mm}$ & 0.2 & $750-775 \mathrm{~mm}$ & 0.4 & $750-1525 \mathrm{~mm}$ & $\begin{array}{c}\text { Single Glazed } \\
\text { Clear/Timber/uPVC/Fiberglass }\end{array}$ \\
\hline $\mathrm{D}$ & 0.2 & 1900-2087.5 mm & 0.4 & $750-1525 \mathrm{~mm}$ & 0.2 & 775-983 mm & 0.4 & $750-1525 \mathrm{~mm}$ & $\begin{array}{c}\text { Single Glazed } \\
\text { Clear/Timber/uPVC/Fiberglass }\end{array}$ \\
\hline
\end{tabular}


All solutions have a WWR of $20 \%$ scheduled for the east- and west-facing walls. An approximately $8.57 \%$ reduction in annual energy consumption is observed for all designs. The strategies utilised in sample designs are consistent with findings from the sensitivity analysis. Design A allocates a $20 \%$ opening area on each façade at middle to high positions, offers double glazed windows to prevent sun exposure and achieves the minimal summer heat gain among the sample designs. On the contrary, design $B$ aims to minimise winter heat loss by placing better thermally insulated timber framed windows. This design permits lower and generous opening to the north to allow for more solar penetration in winter. This effect is strengthened by choosing low window height ranges to the other orientations, which are not as sensitive as the size variables for winter thermal performance in order to avoid noncompliant designs. Designs $\mathrm{C}$ and $\mathrm{D}$ focus on optimising the effective aperture requirement by employing glazing with high VLT value. These two solutions are similar with the only difference being the window height on the western façade. Again, due to the binding thermal and WFR constraints, these two designs opt for leveraging large southern windows instead of installing the more thermally sensitive eastern windows to achieve better daylight performance. As all four are obtained from the Pareto Front, they all represent equally good practices when controlling other design parameters and the results are validated by the energy simulation. It can be concluded that each of the samples is designed in accordance with the variable importance ranking as reported in the sensitivity analysis to deliver the optimal energy performance. Design constraints considered also played a prominent role in determining which variable can be compromised.

\section{Conclusions}

A window design optimisation problem was proposed in this study for the window type, WWR and window height for residential buildings in nontropical regions in Australia using a BIM platform, Revit and its extension Dynamo. Three objective functions concerning the natural light, undesirable heat gain in summer and heat loss in winter together with four penalty functions that impose realistic design constraints were formulated and solved using an NSGA-II optimisation package of Dynamo, Optimo. A range of coefficients offered by the Australian construction regulatory framework, NCC, was adopted to translate the continuous window height variable into discrete values. Architectural model geometries, such as hosting wall areas and heights, were extracted from the building model as optimisation parameters.

The results were presented in the form of Pareto Front with the improvements of design objectives throughout the optimisation process visualized using a 3-dimensional scatter plot. A sensitivity analysis was performed to comprehend the impacts of different variables on each design objective. The most important variables for each design objective are identified, and it was found that northern openings are effective in offering passive heating in winter while the role of the east-facing windows in providing natural daylight is limited due to the potential overheating problem in summer. Additionally, choosing a high-performance window has the most direct impact on eliminating adverse heat gain.

To further showcase the interplay of different design attributes, a sample of four designs identified from the result set was displayed using parallel coordinates. A Revit energy analysis plugin, Insight, was employed to simulate these four designs to get the annual energy consumption in order to contrast the base case. The simulation results suggest that approximately $8.57 \%$ energy reduction could be realized when applying the sample design.

This novel framework responds to the current limitations found in simulation-based optimisation studies by offering a new approach to addressing the current window design challenge with minimal programme dependencies on energy simulation packages. The framework was built upon a commercial software so that the optimisation process can be easily integrated into the design workflow as an easy-to-use tool. The proposed optimisation framework addresses the window size, type and placement height using a very accessible commercial tool while considering a series of constraints, such as design clashes and local compliances. The findings from a case study in a temperate climate region emphasized the importance of window selection and highlighted that results are generally in line with the design 
strategy of leveraging northern windows for winter passive heating. The results also shed some light on the eastern windows' contradicting effects in daylight design and thermal comfort. The proposed workflow has demonstrated the feasibility of conducting a numerical-based design optimisation on a common modelling platform, providing an opportunity for integrating design optimisation into industry practices. However, it is critical to bear in mind that the windows tested in the case study are only suitable to represent the Australian market, and therefore, the result generated are not necessarily applicable to other regions with similar climatic characteristics. Local window configuration data are required when implementing the proposed framework in a foreign context, and these can easily be incorporated by updating the window property parameters, such as the SHGC, VLT and U values in the model.

One weakness of this work is that the optimisation framework developed is only applicable to residential buildings at this stage. As the economic activities that take place in commercial buildings pose very different energy requirements [52], the specific design objectives might vary, and hence, the objective functions need to be reviewed. This leads to a possible extension of the current framework where thermal objectives for commercial buildings can incorporate the SHGC and U values of the building façade, which would also account for the thermal bridging between elements, as opposed to purely focusing on window elements. This would apply more stringent evaluation rules to the thermal performance of the commercial building [73].

Even though the proposed framework is only tested on a simple house, the framework proposed can easily be extended to cover more complicated building configurations such as apartment buildings.

Some other future work built upon this study could involve generalising the proposed Optimo optimisation framework so that designers only need to choose the file paths for variable input, while the remaining process will be competed automatically. Further, the proposed framework could be integrated with the modelling software as an addon and the interaction could be achieved via the use of an Application Programming Interface (API), delivering a fully automated optimisation workflow. A similar interaction was realized by Rahmani Asl, Zarrinmehr, et al. [40] by linking an Optimo framework with Green Building Studio for real-time simulation. However, the connection was discontinued $[88,89]$ due to lack of maintenance, which also sheds light on the importance of continuing collaboration between key industry players and the academia.

Author Contributions: Conceptualization, Z.C. and A.W.A.H.; methodology, Z.C. and A.W.A.H.; software, Z.C.; validation, Z.C., A.W.A.H., I.K. and A.H.; formal Analysis, Z.C.; investigation, Z.C. and A.W.A.H.; resources, Z.C. and A.W.A.H.; data curation, Z.C.; writing-original draft preparation, Z.C. and A.W.A.H.; writing-review and editing, Z.C., A.W.A.H., I.K. and A.H.; visualization, Z.C., A.W.A.H. and A.H.; supervision, A.W.A.H. and A.H.; project administration, A.W.A.H. and I.K.; funding acquisition, A.W.A.H. All authors have read and agreed to the published version of the manuscript.

Funding: This research was funded by UNSW Built Environment Limited APC Scheme.

Conflicts of Interest: The authors declare no conflict of interest.

\section{Nomenclature}

$\begin{array}{ll}\text { ABBREVIATIONS } & \\ \text { BIM } & \text { Building Information Modelling } \\ \text { CSV } & \text { Comma-separated Value file format } \\ \text { GBI } & \text { Green Building Initiative } \\ \text { HVAC } & \text { Heating, ventilation and air conditioning } \\ \text { IFC } & \text { Industry Foundation Classes } \\ \text { MOO } & \text { Multi-objective Optimisation } \\ \text { NCC } & \text { National Construction Code } \\ \text { NSGA-II } & \text { Non-Dominated Sorting Genetic Algorithm } \\ \text { SHGC } & \text { Solar Heat Gain Coefficient } \\ \text { SRC } & \text { Standardised Regression Coefficients } \\ \text { VLT } & \text { Visual Light Transmittance }\end{array}$


VPL

U

WFR

WWR

SET

$i \in\{1 \ldots n\}, i \in N$

OBJECTIVE FUNCTIONS

EA

$H G^{\prime}$

$H L^{\prime}$

HL

HG

VARIABLES

VLT

SHGC

$U$

$W W R_{i}$

$E S_{i}$

$E W_{i}$

$\delta_{g}$

$\delta_{l}$

$\delta_{h}$

$\delta_{f}$

\section{PARAMETERS}

WA

I

$p$

$h$

$A_{i}$

$H_{i}$

WP

$W_{i}$

$\overline{\overline{W H_{i}}}$

$\underline{\underline{W F R}}$

$\overline{W F R}$

$F$

$\overline{H G}$

$C_{\text {SHGC }}$

$\overline{\mathrm{CON}}$

$c_{U}$

\section{$P$}

PENALTY FUNCTIONS

$f_{p 1}(H G)$

$f_{p 2}(H L)$

$f_{p 3}(E A)$
Visual Programming Language

Overall Heat Transfer Coefficient

Window-to-Floor Ratio

Window-to-Wall Ratio

Set of walls with windows scheduled on each story

Effective aperture calculated on each floor

A general function for calculating overall heat gain in Watts

A general function for calculating overall heat loss in Watts

Winter heat loss calculated on each floor

Summer heat gain calculated on each floor

Visual light transmittance for the window system

Solar heat gain coefficient for the window system

Overall heat transfer coefficient for the window system $\left(\mathrm{W} / \mathrm{m}^{2} \cdot \mathrm{K}\right)$

WWR scheduled for the wall $i$

Summer exposure factor of the wall $i$

Winter exposure factor of the wall $i$

Binary variable which is equal to 1 when summer heat gain exceeds the maximum value allowed, and 0 otherwise

Binary variable which is equal to 1 when winter heat loss exceeds the maximum value allowed, and 0 otherwise

Binary variable which is equal to one when the window placement constraint is violated, and 0 otherwise

Binary variable which is equal to one when the window-to-floor ratio constraint is violated, and 0 otherwise

Total window area on each story

Solar irradiance

The width of the shading device

The distance between the base of the window to the bottom of the

shading device

Gross area of the hosting wall $i$

Height of the hosting wall $i$

A hypothetical working plane determined by the designer

Lower bound for window placement on the wall $i$

Upper bound for window placement on the wall $i$

The minimum WFR specified by the designer

The maximum WFR specified by the designer

The fully enclosed covered area on each floor

Maximum value allowed for summer heat gain

Deemed-to-satisfy constant for calculating summer heat gain obtained

from the National Construction Code (NCC)

Maximum value allowed for winter heat loss

Deemed-to-satisfy constant for calculating winter heat loss obtained from

the National Construction Code (NCC)

Constant penalty

Penalty function applied to the design objective summer heat gain

Penalty function applied to the design objective winter heat loss

Penalty function applied to the design objective effective aperture 


\section{References}

1. UNEP DTIE Sustainable Consumption \& Production Branch. Buildings and Climate Change Summary for Decision-Makers (p. 5). United Nations Environment Programme. 2009. Available online: https: //ledsgp.org/wp-content/uploads/2015/07/buildings-and-climate-change.pdf (accessed on 16 November 2020).

2. US Energy Information Administration. International Energy Outlook 2016 (p. 101). US Enegry Information Administration. 2015. Available online: https://www.eia.gov/outlooks/ieo/pdf/buildings.pdf (accessed on 16 November 2020).

3. Australian Building Codes Board. $A B C B$ Building Classifications; Australian Building Codes Board: Canberra, Australian, 2020.

4. Energy Account, Australia, 2017-2018 Financial Year|Australian Bureau of Statistics. Available online: https://www.abs.gov.au/statistics/industry/energy/energy-account-australia/latest-release (accessed on 12 November 2019).

5. Tian, Z.; Zhang, X.; Jin, X.; Zhou, X.; Si, B.; Shi, X. Towards adoption of building energy simulation and optimization for passive building design: A survey and a review. Energy Build. 2018, 158, 1306-1316. [CrossRef]

6. Gou, S.; Nik, V.M.; Scartezzini, J.-L.; Zhao, Q.; Li, Z. Passive design optimization of newly-built residential buildings in Shanghai for improving indoor thermal comfort while reducing building energy demand. Energy Build. 2018, 169, 484-506. [CrossRef]

7. AlBayyaa, H.; Hagare, D.; Saha, S. Energy conservation in residential buildings by incorporating Passive Solar and Energy Efficiency Design Strategies and higher thermal mass. Energy Build. 2019, 182, $205-213$. [CrossRef]

8. Cuce, E. Role of airtightness in energy loss from windows: Experimental results from in-situ tests. Energy Build. 2017, 139, 449-455. [CrossRef]

9. Arasteh, D.; Selkowitz, S.; Apte, J.; LaFrance, M. Zero Energy Windows; Ernest Orlando Lawrence Berkeley National Laboratory: Berkeley, CA, USA, 2006; Volume 14.

10. Johnston, D.; Zhang, H.; Airah, M.; Wang, G.; Bannister, P.; Airah, F. Glazing Studies for The National Construction Code 2019. In Proceedings of the AIRAH and IBPSA's Australasian Building Simulation 2017 Conference, Melbourne, Australia, 15-16 November 2017.

11. Chen, X.; Yang, H.; Wang, T. Developing a robust assessment system for the passive design approach in the green building rating scheme of Hong Kong. J. Clean. Prod. 2017, 153, 176-194. [CrossRef]

12. Kolarik, J.; Toftum, J.; Olesen, B.W.; Jensen, K.L. Simulation of energy use, human thermal comfort and office work performance in buildings with moderately drifting operative temperatures. Energy Build. 2011, 43, 2988-2997. [CrossRef]

13. Kim, S.; Zadeh, P.A.; Staub-French, S.; Froese, T.M.; Cavka, B.T. Assessment of the Impact of Window Size, Position and Orientation on Building Energy Load Using BIM. Procedia Eng. 2016, 145, 1424-1431. [CrossRef]

14. Ashrafian, T.; Moazzen, N. The impact of glazing ratio and window configuration on occupants' comfort and energy demand: The case study of a school building in Eskisehir, Turkey. Sustain. Cities Soc. 2019, 47, 101483. [CrossRef]

15. Mahar, W.A.; Verbeeck, G.; Reiter, S.; Attia, S. Sensitivity Analysis of Passive Design Strategies for Residential Buildings in Cold Semi-Arid Climates. Sustainability 2020, 12, 1091. [CrossRef]

16. Reilly, M.; Winkelmann, F.; Arasteh, D.; Carroll, W. Modeling windows in DOE-2.1E. Energy Build. 1995, 22, 59-66. [CrossRef]

17. Cheung, C.; Fuller, R.; Luther, M. Energy-efficient envelope design for high-rise apartments. Energy Build. 2005, 37, 37-48. [CrossRef]

18. Dutta, A.; Samanta, A. Reducing cooling load of buildings in the tropical climate through window glazing: A model to model comparison. J. Build. Eng. 2018, 15, 318-327. [CrossRef]

19. Bokel, R.M.J. The Effect of Window Position and Window Size on The Energy Demand for Heating, Cooling and Electric Lighting. Build. Simulat. 2007, 10, 117-121.

20. Sun, Y.; Shanks, K.; Baig, H.; Zhang, W.; Hao, X.; Li, Y.; He, B.; Wilson, R.; Liu, H.; Sundaram, S.; et al. Integrated semi-transparent cadmium telluride photovoltaic glazing into windows: Energy and daylight performance for different architecture designs. Appl. Energy 2018, 231, 972-984. [CrossRef] 
21. Thalfeldt, M.; Kurnitski, J.; Voll, H. Detailed and simplified window model and opening effects on optimal window size and heating need. Energy Build. 2016, 127, 242-251. [CrossRef]

22. National Construction Code Energy efficiency NCC Volume Two. Australian Building Codes Board. 2019. Available online: https://www.abcb.gov.au/Resources/Publications/Education-Training/energy-efficiencyncc-volume-two (accessed on 16 November 2020).

23. York, R.; Rosa, E.A.; Dietz, T. STIRPAT, IPAT and ImPACT: Analytic tools for unpacking the driving forces of environmental impacts. Ecol. Econ. 2003, 46, 351-365. [CrossRef]

24. Statistics, Commonwealth of Australia. Main Features-Climate zone. $\mathrm{c}=\mathrm{AU}$; $\mathrm{o}=\mathrm{Commonwealth}$ of Australia; ou=Australian Bureau of Statistics. Available online: https://www.abs.gov.au/ausstats/abs@.nsf/Lookup/by\% 20Subject/4671.0 \{\}2012 \{\}Main\%20Features \{\}Climate\%20zone \{\}17 (accessed on 24 September 2013).

25. Nguyen, A.-T.; Reiter, S.; Rigo, P. A review on simulation-based optimization methods applied to building performance analysis. Appl. Energy 2014, 113, 1043-1058. [CrossRef]

26. Attia, S.; Hamdy, M.; O’Brien, W.; Carlucci, S. Computational Optimisation for Zero Energy Buildings Design: Inerviews Results with Twenty Eight International Experts. In Proceedings of the 13th Conference of International Building Performance Simulation Association, Chambery, France, 26-28 August 2013.

27. Attia, S.; Hamdy, M.; O’Brien, W.; Carlucci, S. Assessing gaps and needs for integrating building performance optimization tools in net zero energy buildings design. Energy Build. 2013, 60, 110-124. [CrossRef]

28. Autodesk. Revit|BIM Software|Autodesk Official Store. 2020. Available online: https://www.autodesk.com/ products/revit/overview (accessed on 16 November 2020).

29. Autodesk. Dynamo. Dynamo BIM. 2020. Available online: https://dynamobim.org/download/ (accessed on 16 November 2020).

30. Robert McNeel \& Associates. Rhino Features. 2020. Available online: https://www.rhino3d.com/6/features (accessed on 16 November 2020).

31. Octopus. [Text]. Food4Rhino. Available online: https://www.food4rhino.com/app/octopus (accessed on 6 December 2012).

32. Galapagos-Addon for Grasshopper. Grasshopper Docs. Available online: http://grasshopperdocs.com/ addons/galapagos.html (accessed on 15 December 2019).

33. Rahmani Asl, M.; Stoupine, A.; Zarrinmehr, S.; Yan, W. Optimo: A BIM-based multi-objective optimization tool utilizing visual programing for high performance building design. In Proceedings of the Conference of Education and Research in Computer Aided Architectural Design in Europe (ECAADe), Vienna, Austria, 16-18 September 2015; pp. 673-682.

34. Robert McNeel \& Associates. Grasshopper-New in Rhino 6. February 2018. Available online: https: //www.rhino3d.com/6/new/grasshopper (accessed on 16 November 2020).

35. Kensek, K. Visual Programming for Building Information Modeling: Energy and Shading Analysis Case Studies. J. Green Build. 2015, 10, 28-43. [CrossRef]

36. Kensek, K.M. Integración de sensores medioambientales con BIM: Casos de estudio usando Arduino, Dynamo, y Revit API. Informes de la Construcción 2014, 66, 44. [CrossRef]

37. Shadram, F.; Mukkavaara, J. An integrated BIM-based framework for the optimization of the trade-off between embodied and operational energy. Energy Build. 2018, 158, 1189-1205. [CrossRef]

38. Cheng, C.; Ninic, J.; Tizani, W. Parametric Virtual Design-Based Multi-Objective Optimization for Sustainable Building Design. In Proceedings of the EG-ICE 2019 Workshop on Intelligent Computing in Engineering, Leuven, Belgium, 5 July 2019.

39. Touloupaki, E.; Theodosiou, T. Performance Simulation Integrated in Parametric 3D Modeling as a Method for Early Stage Design Optimization-A Review. Energies 2017, 10, 637. [CrossRef]

40. Asl, M.R.; Zarrinmehr, S.; Bergin, M.; Yan, W. BPOpt: A framework for BIM-based performance optimization. Energy Build. 2015, 108, 401-412. [CrossRef]

41. Ma, Q.; Fukuda, H. Parametric Office Building for Daylight and Energy Analysis in the Early Design Stages. Procedia Soc. Behav. Sci. 2016, 216, 818-828. [CrossRef]

42. Fang, Y.; Cho, S. Design optimization of building geometry and fenestration for daylighting and energy performance. Sol. Energy 2019, 191, 7-18. [CrossRef]

43. Shahbazi, Y.; Heydari, M.; Haghparast, F. An early-stage design optimization for office buildings' façade providing high-energy performance and daylight. Indoor Built Environ. 2019, 28, 1350-1367. [CrossRef] 
44. Larson, G.W.; Shakespeare, R.A. Rendering with Radiance. Available online: https://floyd.lbl.gov/radiance/ book/index.html (accessed on 16 November 2020).

45. OpenStudio. Available online: https://www.openstudio.net/ (accessed on 27 April 2020).

46. James, J.; Hirsch \& Associates. DOE2.com Home Page. The Home of DOE-2 Based Building Energy Use and Cost Analysis Software. 2016. Available online: http://www.doe2.com/ (accessed on 16 November 2020).

47. The Dynamo Primer. Autodesk Dynamo Developmet Team. 2019. Available online: https://primer. dynamobim.org/index.html (accessed on 16 November 2020).

48. Johnson, R.; Sullivan, R.; Selkowitz, S.; Nozaki, S.; Conner, C.; Arasteh, D. Glazing energy performance and design optimization with daylighting. Energy Build. 1984, 6, 305-317. [CrossRef]

49. Lee, J.W.; Park, J.; Jung, H.-J. A feasibility study on a building's window system based on dye-sensitized solar cells. Energy Build. 2014, 81, 38-47. [CrossRef]

50. Levine, M.D.; Busch, J.F. Building Energy Conservation Project (Volume II: Techonology). Energy Analysis Program, Energy and Environment Division, Lawrence Berkeley Laboratory; Levine, M.D., Busch, J.F., Eds.; University of California: Oakland, CA, USA, 1992. Available online: https://www.osti.gov/servlets/purl/10163215\#page= 178 (accessed on 16 November 2020).

51. Sullivan, R.; Lee, E.; Selkowitz, S. A Method of Optimizing Solar Control and Daylighting Performance in Commercial Office Buildings. In Proceedings of the Thermal Performance of the Exterior Envelopes of Buildings V Conference, Clearwater Beach, FL, USA, 7-10 December 1992.

52. The role of Energy Conservation Building Code 2017 in Indian Energy Policy. Int. J. Recent Technol. Eng. 2020, 9, 1799-1806. [CrossRef]

53. Robinson, A.; Selkowitz, S. Tips for daylighting with windows (LBNL-6902E, 1167562; p. LBNL-6902E, 1167562). 2013. Available online: https://doi.org/10.2172/1167562 (accessed on 16 November 2020).

54. Rubin, M. Calculating heat transfer through windows. Int. J. Energy Res. 1982, 6, 341-349. [CrossRef]

55. Chen, X.; Yang, H.; Lu, L. A comprehensive review on passive design approaches in green building rating tools. Renew. Sustain. Energy Rev. 2015, 50, 1425-1436. [CrossRef]

56. National Construction Code NCC Volume Two. Australian Building Codes Board. 2019. Available online: https://ncc.abcb.gov.au/ (accessed on 16 November 2020).

57. Acosta, I.; Campano, M.Á.; Molina, J.F. Window design in architecture: Analysis of energy savings for lighting and visual comfort in residential spaces. Appl. Energy 2016, 168, 493-506. [CrossRef]

58. Deb, K.; Pratap, A.; Agarwal, S.; Meyarivan, T. A fast and elitist multiobjective genetic algorithm: NSGA-II. IEEE Trans. Evolut. Comput. 2002, 6, 182-197. [CrossRef]

59. Aish, R. DesignScript User Manual. Available online: https://www.researchgate.net/publication/320346998_ DesignScript_User_Manual (accessed on 16 November 2020).

60. Li, H.W.; Lam, J.; Wong, S. Daylighting and its effects on peak load determination. Energy 2005, 30, $1817-1831$. [CrossRef]

61. ANSI/GBI 01-2019: Green Globes Assessment Protocol for Commercial Buildings. Green Building Initiative. 2019. Available online: https://thegbi.org/content/misc/ANSI-GBI_01-2019_Publication_-_final_6-14-19_.pdf (accessed on 16 November 2020).

62. ANSI/GBI 01-2010 Green Building Assessment Protocol for Commercial Buildings. Green Building Initiative. 2010. Available online: https://thegbi.org/content/misc/GBI_ANSI_procedures_GBI-PRO_2015_-_ANSI_ approved_2-4-162.pdf (accessed on 16 November 2020).

63. ASHRAE Standards Committee 2019-2020. ANSI/ASHRAE/IES Standard 90.1-2019 Energy Standard for Buildings Except Low-Rise Residential Buildings (I-P Edition). American Society of Heating, Refrigerating and Air-Conditioning Engineers, Inc. 2019. Available online: https://ashrae.iwrapper.com/ViewOnline/ Standard_90.1-2019 (accessed on 16 November 2020).

64. Klems, J.H. U-Values, Solar Heat Gain, and Thermal Performance: Recent Studies Using the MoWiTT. Available online: https://escholarship.org/content/qt1xn2n0d6/qt1xn2n0d6.pdf?t=p0hi3n (accessed on 16 November 2020).

65. Szokolay, S. Introduction to Architectural Science; Informa UK Limited: London, UK, 2014.

66. Page, A.; Moghtaderi, B.; Alterman, D.; Hands, S. A study of the Thermal Performance of Australian Housing. 2011. Available online: https://nova.newcastle.edu.au/vital/access/manager/Repository/uon:15617 (accessed on 16 November 2020). 
67. Caldas, L.G.; Norford, L. A design optimization tool based on a genetic algorithm. Autom. Constr. 2002, 11, 173-184. [CrossRef]

68. Hammad, A.; Akbarnezhad, A.; Grzybowska, H.; Wu, P.; Wang, X. Mathematical optimisation of location and design of windows by considering energy performance, lighting and privacy of buildings. Smart Sustain. Built Environ. 2019, 8, 117-137. [CrossRef]

69. Kull, T.M.; Mauring, T.; Tkaczyk, A.H. Energy balance calculation of window glazings in the northern latitudes using long-term measured climatic data. Energy Convers. Manag. 2015, 89, 896-906. [CrossRef]

70. Asadi, E.; Da Silva, M.G.; Antunes, C.H.; Dias, L.C. Multi-objective optimization for building retrofit strategies: A model and an application. Energy Build. 2012, 44, 81-87. [CrossRef]

71. Zain-Ahmed, A.; Sopian, K.; Othman, M.; Sayigh, A.; Surendran, P. Daylighting as a passive solar design strategy in tropical buildings: A case study of Malaysia. Energy Convers. Manag. 2002, 43, 1725-1736. [CrossRef]

72. Nedhal, A.-T.; Syed, F.S.F.; Adel, A. Relationship between Window-to-Floor Area Ratio and Single-Point Daylight Factor in Varied Residential Rooms in Malaysia. Indian J. Sci. Technol. 2016, 9. [CrossRef]

73. NCC 2019 Guide to BCA Volume One; Australian Building Codes Board: Canberra, Australian, 2019.

74. Blasco, X.; Herrero, J.; Sanchis, J.; Martínez, M. A new graphical visualization of n-dimensional Pareto front for decision-making in multiobjective optimization. Inf. Sci. 2008, 178, 3908-3924. [CrossRef]

75. Australian Building Codes Board. New South Wales Australian Capital Territory Climate Zone Map. Australian Building Codes Board. 2019. Available online: https://www.abcb.gov.au/Resources/ToolsCalculators/Climate-Zone-Map-Australia-Wide (accessed on 16 November 2020).

76. Wang, W.; Zmeureanu, R.; Rivard, H. Applying multi-objective genetic algorithms in green building design optimization. Build. Environ. 2005, 40, 1512-1525. [CrossRef]

77. Australian Fenestration Rating Council. Release of Defaults-AFRC Industry Announcement. 2014. Available online: https://www.afti.edu.au/documents/item/735 (accessed on 16 November 2020).

78. Glazing|YourHome. 2013. Available online: https://www.yourhome.gov.au/passive-design/glazing (accessed on 16 November 2020).

79. Tabrizi, T.B.; Hill, G.; Aitchison, M. The Impact of Different Insulation Options on the Life Cycle Energy Demands of a Hypothetical Residential Building. Procedia Eng. 2017, 180, 128-135. [CrossRef]

80. Philip, H. Accelerating Net-Zero High-Rise Residential Buildings in Australia (Final Report, p. 9). City of Sydney. 2016. Available online: https://www.cityofsydney.nsw.gov.au/_data/assets/pdf_file/0005/264398/ Accelerating-Net-Zero-High-Rise-Residential-Buildings.pdf (accessed on 16 November 2020).

81. King, S. Daylight \& Solar Access. Reading between the Lines: Making Sense of Consultant Reports-Understanding the Environmental Sciences Essential to Development Applications. Neerg Seminar: Reading between the Lines: Making Sense of Consultant Reports-Understanding the Environmental Sciences Essential to Development Applications; 2006; August, Sydney. 2006. Available online: http: //unsworks.unsw.edu.au/fapi/datastream/unsworks:5026/SOURCE01?view=true (accessed on 16 November 2020).

82. Ibrahim, N.L.N.; Hayman, S. Latitude variation and its influence on rules of thumb in daylighting. Arch. Sci. Rev. 2010, 53, 408-414. [CrossRef]

83. Wang, M.; Gene, C.T. Applied Physics for Architecture; Tai Long book Co.: Hong Kong, China, 1987.

84. Orientation|YourHome. 2013. Available online: https://www.yourhome.gov.au/passive-design/orientation (accessed on 16 November 2020).

85. Tian, W. A review of sensitivity analysis methods in building energy analysis. Renew. Sustain. Energy Rev. 2013, 20, 411-419. [CrossRef]

86. Nguyen, A.-T.; Reiter, S. A performance comparison of sensitivity analysis methods for building energy models. Build. Simul. 2015, 8, 651-664. [CrossRef]

87. Gagnon, R.; Gosselin, L.; Decker, S. Sensitivity analysis of energy performance and thermal comfort throughout building design process. Energy Build. 2018, 164, 278-294. [CrossRef] 
88. Autodesk. Insight|Building Performance Analysis Software|Autodesk. 2020. Available online: https: //www.autodesk.com/products/insight/overview (accessed on 16 November 2020).

89. Alternative GBS Runs Energy Analysis. Dynamo. Available online: https://forum.dynamobim.com/t/ alternative-gbs-runs-energy-analysis/7823 (accessed on 29 November 2016).

Publisher's Note: MDPI stays neutral with regard to jurisdictional claims in published maps and institutional affiliations.

(C) 2020 by the authors. Licensee MDPI, Basel, Switzerland. This article is an open access article distributed under the terms and conditions of the Creative Commons Attribution (CC BY) license (http://creativecommons.org/licenses/by/4.0/). 